\title{
LA RECONQUÊTE BYZANTINE DE LA SYRIE À LA LUMIÈRE DES SOURCES ÉPIGRAPHIQUES : AUTOUR DE BALĀṬUNUS (QAL‘AT MEHELBÉ)
}

\author{
Julien Aliquot et Zaza AleksidzÉ
}

Contrairement aux autres régions du Proche-Orient, la Syrie côtière, l'Antiochène et la vallée de l'Oronte livrent quelques inscriptions grecques des $10^{\mathrm{e}}$ et $11^{\mathrm{e}}$ siècles ${ }^{1}$. Ces textes, dont on trouvera la liste en appendice, complètent nos connaissances sur la période au cours de laquelle Byzance a reconquis la région sur les Hamdanides et les Fatimides, entre le règne de Nicéphore II Phocas, dans les années 960, et l'arrivée des Turcs seldjoukides, dans les années 1070-1080². En 969, avec la prise d'Antioche, et jusqu'en 1084-1085, l'Empire retrouve un second siège patriarcal et peut espérer récupérer toute la Syrie. Pendant un siècle, les Byzantins s'y emploient en s'appuyant sur les communautés chrétiennes locales, auxquelles ils permettent de

1. Cet article n'aurait pas vu le jour sous sa forme actuelle sans l'accord bienveillant de la Direction générale des Antiquités et des Musées de Syrie, en particulier de MM. Bassam Jamous (Directeur général), Michel Al-Maqdissi (Directeur des fouilles et des études archéologiques), Jamal Haydar (Directeur du Département des Antiquités de Lattaquié) et de Mme Hayfa Chabane (Conservatrice du musée archéologique de Lattaquié), ni sans le généreux concours de M. Jean-Pierre Mahé (École pratique des hautes études), qui nous a mis en contact mutuel et nous a fait part de ses observations. Notre travail commun a également bénéficié des remarques de MM. Jean-Claude Cheynet (Université de Paris-Sorbonne), Denis Feissel (École pratique des hautes études, Paris), Pierre-Louis Gatier (HiSoMA, Lyon), Benjamin Michaudel et Bruno Paoli (Institut français du Proche-Orient, Damas). Que tous reçoivent l'expression de notre gratitude. Nous nous sommes réparti les tâches en fonction de nos aptitudes. J. Aliquot s'est occupé de la partie grecque de l'inscription de Balātunus dont la publication prépare la réédition du tome des Inscriptions grecques et latines de la Syrie (IGLS) consacré à la Syrie côtière, ainsi que du traitement des sources arabes et grecques, tandis que Z. Aleksidzé s'est chargé de la lecture de la partie géorgienne de ce texte et des sources géorgiennes et arméniennes. Il va de soi cependant que nous assumons ensemble la responsabilité des propositions réunies sous nos deux noms.

2. Pour les événements, voir les ouvrages classiques de G. SCHLumberger, L'épopée byzantine à la fin du dixième siècle, I-III, Paris 1896-1905; E. Honigmann, Die Ostgrenze des byzantinischen Reiches von 363 bis 1071, Bruxelles 1935; M. CANARD, Histoire de la dynastie des H'amdanides de Jâzira et de Syrie, Alger 1951; A. A. VAsILIEv, Byzance et les Arabes, I-II, Bruxelles 1935-1968; ainsi que W. Felix, Byzanz und die islamische Welt im früheren 11. Jahrhundert, Vienne 1981; Th. Bianquis, Damas et la Syrie sous la domination des Fatimides (359-458/969-1076), Damas 1986-1989; Le Monde byzantin. II, L'Empire byzantin (641-1204), éd. J.-C. Cheynet, Paris 2006, en particulier les chapitres 2-3 (J.-C. CheYnet) et 16 (B. MartinHISARD). 
fonder des évêchés et des monastères, mais aussi, le cas échéant, sur des mercenaires étrangers, en particulier pour s'assurer le contrôle des tribus arabes musulmanes dans les secteurs les plus confinés du pays ${ }^{3}$. Le rôle que les Syriens jacobites ${ }^{4}$, les Arméniens ${ }^{5}$, les Francs ${ }^{6}$, les Turcs ${ }^{7}$ et les Arabes ${ }^{8}$ ont joué dans ce contexte est bien connu. Celui des Géorgiens l'est moins. Une inscription bilingue inédite grecque et géorgienne de Balātunus nous donne l'occasion de l'évoquer.

Balātunus, aujourd'hui Qal'at Mehelbé, domine, à $11 \mathrm{~km}$ au sud de Haffé et à $3 \mathrm{~km}$ au nord-est de Qerdaha, les plaines côtières de Laodicée (alLādiqiyya, Lattaquié) et de Gabala (Ǧabala, Jablé) ${ }^{9}$. Établi à environ $775 \mathrm{~m}$ d'altitude sur une butte-témoin constituant l'un des deux sommets du Jabal alArbain, massif secondaire de la chaîne des montagnes côtières de la Syrie (Jabal al-Saheliyé), ce site fortifié est étroitement lié aux deux cités de Gabala

3. Sur Antioche et son duché à l'époque de la Reconquête byzantine, voir en dernier lieu K.-P. TodT, Region und griechisch-orthodoxes Patriarchat von Antiocheia in mittelbyzantinischer Zeit und im Zeitalter der Kreuzzüge (969-1204), BZ 94, 2001, p. 239-267 ; IDEM, Antioch in the Middle Byzantine period (969-1084): the reconstruction of the city as an administrative, economic, military and ecclesiastical center, dans Antioche de Syrie (Topoi Suppl.5), éd. B. Cabouret, P.-L. Gatier et C. Saliou, Lyon 2004, p. 171-190; J.-C. Cheynet, The Duchy of Antioch during the Second Period of Byzantine Rule, dans East and West in the Medieval Eastern Mediterranean. I, Antioch from the Byzantine Reconquest until the end of the Crusader principality, éd. K. N. Ciggaar et D. M. Metcalf, Louvain 2006, p. 1-16.

4. G. Dagron, Minorités ethniques et religieuses dans l'Orient byzantin à la fin du $\mathrm{X}^{\mathrm{e}}$ et au $\mathrm{XI}^{\mathrm{e}}$ siècle: l'immigration syrienne, TM 6, 1976, p. 177-216, repris dans La romanité chrétienne en Orient, Londres 1984, article X.

5. N.G. GARSOÏAN, The Problem of Armenian Integration into the Byzantine Empire, dans Studies on the internal diaspora of the Byzantine Empire, éd. H. AHrwEILER et A. E. LAIOU, Washington 1998, p. 53-124; G. DÉDÉYAN, Le rôle des Arméniens en Syrie du Nord pendant la reconquête byzantine (vers 945-1031), BF 25, 1999, p. 249-284; IDEM, Les Arméniens entre Grecs, musulmans et croisés, Lisbonne 2003; J. J. S. WeitenberG, The Armenian monasteries in the Black Mountains, dans East and West in the Medieval Eastern Mediterranean, I, éd. K. N. Ciggaar et D. M. Metcalf, Louvain 2006, p. 79-92.

6. J.SHEPARD, The Uses of the Franks in Eleventh-Century Byzantium, dans Anglo-Norman Studies, XV, éd. M. ChiBnall, Woodbridge 1993, p. 275-305.

7. C. M. Brand, The Turkish Element in Byzantium, Eleventh-Twelfth Centuries, DOP 43, 1989, p. 1-25.

8. J.-C. Cheynet, L'apport arabe à l'aristocratie byzantine des $\mathrm{X}^{\mathrm{e}}-\mathrm{XI}^{\mathrm{e}}$ siècles, $B S$ 56, 1995, p. 137-146, repris et complété dans La société byzantine. L'apport des sceaux, Paris 2008, p. 627-646.

9. M. van Berchem, Inscriptions arabes de Syrie, Mémoires de l'Institut égyptien 3, 1896, p. 490-505 et 516-520; M. van Berchem et E. FATIo, Voyage en Syrie, I, Le Caire 1913, p. 283288; M. Gaudefroy-Demombynes, La Syrie à l'époque des Mamelouks d'après les auteurs arabes, Paris 1923, p. 113, 226-227 et 249; R. Dussaud, Topographie historique de la Syrie antique et médiévale, Paris 1927, p. 150; P. JACQUOT, L'État des Alaouites, Paris 1929, p. 223224; J. Weulersse, Le pays des Alaouites, Tours 1940, p. 94, 98, 104-105, 108, 296, pl. 67; C. CAhen, La Syrie du Nord à l'époque des Croisades et la Principauté franque d'Antioche, Paris 1940, p. 160, 168-173, 278, 329, 353, 429, 538, 706; J. Sourdel-Thomine, Balātunus, EI 1, 1960, p. 1020; P. Deschamps, La défense du comté de Tripoli et de la principauté d'Antioche, Paris 1973, p. 339-340; Th. BIANQUIS, Damas et la Syrie sous la domination des Fatimides, Damas 1986-1989, p.480-487; J.-P. FouRdRIN, L'association de la niche et de 1'archère dans les fortifications élevées en Syrie entre le VI et le XII siècle, Syria 75, 1998, p. 279294, en particulier p. 282-283. 
et de Laodicée. Il occupe une position-clef sur la route qui mène du littoral à la vallée de l'Oronte via Burzay. Le géographe arabe al-Dimašqī, qui le présente comme une citadelle imprenable défendue par une succession de onze portes, décrit Jablé comme le port de Balātunus, au début du $14^{\mathrm{e}}$ siècle $^{10}$. Les vestiges conservés sur place portent la trace de remaniements architecturaux qui sont autant de témoins d'une histoire mouvementée.

Le site a été identifié par M. Hartmann lors d'un voyage effectué en novembre 1881 , d'après l'inscription arabe du début du $14^{\mathrm{e}}$ siècle qui lui donne son nom ancien et que ce savant orientaliste avait repérée dans le hameau voisin de Dibcho ${ }^{11}$. Ses premiers aménagements connus sont cependant bien antérieurs à l'époque mamelouke, puisqu'ils remontent au début du $11^{\mathrm{e}}$ siècle. On ne sait rien de la citadelle de cette époque, sinon qu'elle est occupée par la tribu des Banū l-Aḥmar, qui ont commencé à la fortifier, avant qu'elle soit prise et reconstruite par les Byzantins en 1031. L'épisode, loin d'être isolé, fait partie d'une série d'événements au cours desquels Nicétas de Mistheia, le duc d'Antioche, tente avec plus ou moins de succès de conforter ses positions dans la montagne au nom de l'empereur Romain III Argyre (1028-1034). Il est surtout connu à travers la chronique d'un historien arabe melkite contemporain des faits, Yahyā b. Sa'īd d'Antioche (mort vers 1066) ${ }^{12}$, dont nous citerons bientôt le récit très détaillé. Ensuite, Balāțunus a

10. Al-DimašQī, Cosmographie, VII, 9, éd. A. F. Mehren, Saint-Pétersbourg 1866, p. 208209, trad. IDEM, Manuel de la cosmographie du moyen âge, Copenhague, Leipzig et Paris 1874 , p. 284-285.

11. M. Hartmann, Das Liwa el-Ladkije und die Nahije Urdu, Zeitschrift des deutschen Palästina-Vereins (ci-après ZDPV) 14, 1891, p. 180 (24 novembre); cf. M. VAN BERCHEM, Recherches archéologiques en Syrie. Lettre à M. Barbier de Meynard, Journal Asiatique, 1895, p. 506-507. Trois inscriptions arabes découvertes aux alentours et provenant du château sont publiées par M. VAN BERCHEM, Inscriptions arabes de Syrie, Mémoires de l'Institut égyptien 3, 1896, p. 499-505, pl. 8, et reprises sans changement dans É. Combe, J. SAuvaget et G. WiET, Répertoire chronologique d'épigraphie arabe, XII, Le Caire 1943, p. 65, n 4488 (construction d'une mosquée en 1262); XIII, 1946, p. 38-39, nº 4855 (construction d'un canal en juillet 1285); XIV, 1954, p. 21-22, no 5234 (restauration d'une mosquée par le lieutenant de Balātunus en 1308). Le voyageur américain E. Smith, dont C. RITTER (Die Erdkunde im Verhältniss zur Natur und zur Geschichte des Menschen, oder allgemeine vergleichende Geographie. XVII, Die Sinai-Halbinsel, Palästina und Syrien, 1, Berlin 1854, p. 914 [Muheilibeh]) utilise le récit inédit, signale au-dessus de la porte du château une inscription arabe que personne n'a revue depuis son passage en 1848. Le dégagement de l'entrée monumentale d'époque mamelouke a révélé récemment l'existence de nouveaux textes arabes dont la publication apportera sans doute des informations intéressantes sur ce point.

12. Histoire de Yahya-ibn-Sa id d'Antioche continuateur de Sa ïd-ibn-Bitriq, éd. du texte arabe et trad. française par I. KRATChKovsky et A. VAssiliev, fascicule 1, PO 18, 5, Paris 1923, p. 699-833, et fascicule 2, PO 23, 3, Paris 1932, p. 345-520; Histoire de Yahyā ibn Sa' $\bar{\imath} d$ d'Antioche, édition préparée par I. KRATCHKOVSKY, traduction française annotée par F. MichEAU et G. Troupeau, fascicule 3, PO 47, 4, Turnhout 1997, p. 373-559. La chronique, telle qu'elle nous est parvenue, couvre les années 937-938 à 1033-1034. Nous la citons de cette manière: YAHYĀ, Histoire, avec le numéro du fascicule, puis la pagination originale et celle du fascicule entre crochets. Sur l'auteur et son œuvre: A. A. VAsILIEv, Byzance et les Arabes. II, La dynastie macédonienne (867-959). 2, Extraits des sources arabes, par M. CANARD, Bruxelles 1950, p. 8091 ; M. CAnard, al-Anțākī, $E I^{2}$ 1, 1960, p. 531-532; F. Micheau et G. Troupeau, Introduction, dans YAHYĀ, Histoire, III, p. 373-380 [5-12]; F. Micheau, Les guerres arabo-byzantines vues 


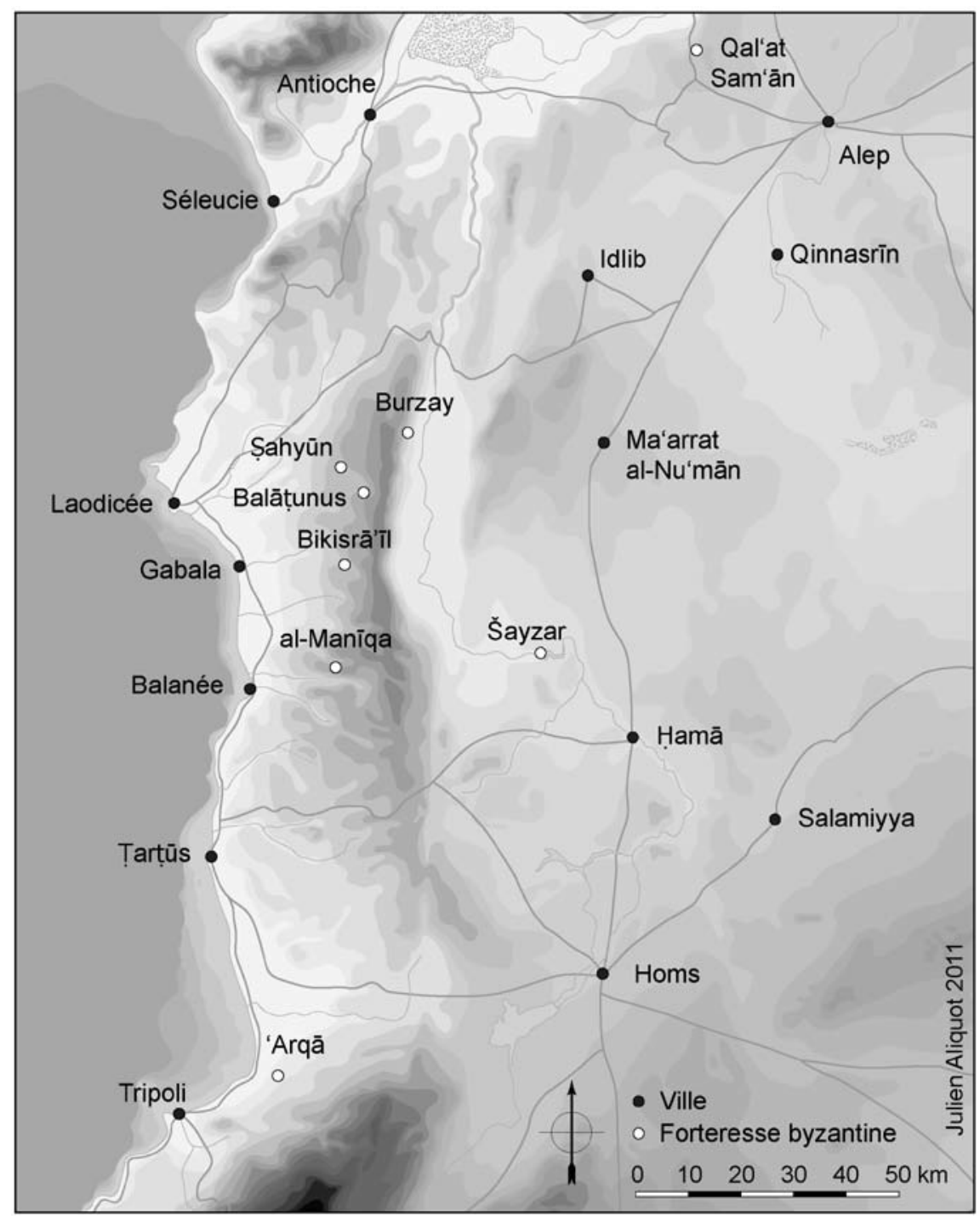

Fig. 1. Carte de situation (J. Aliquot, 2011) 


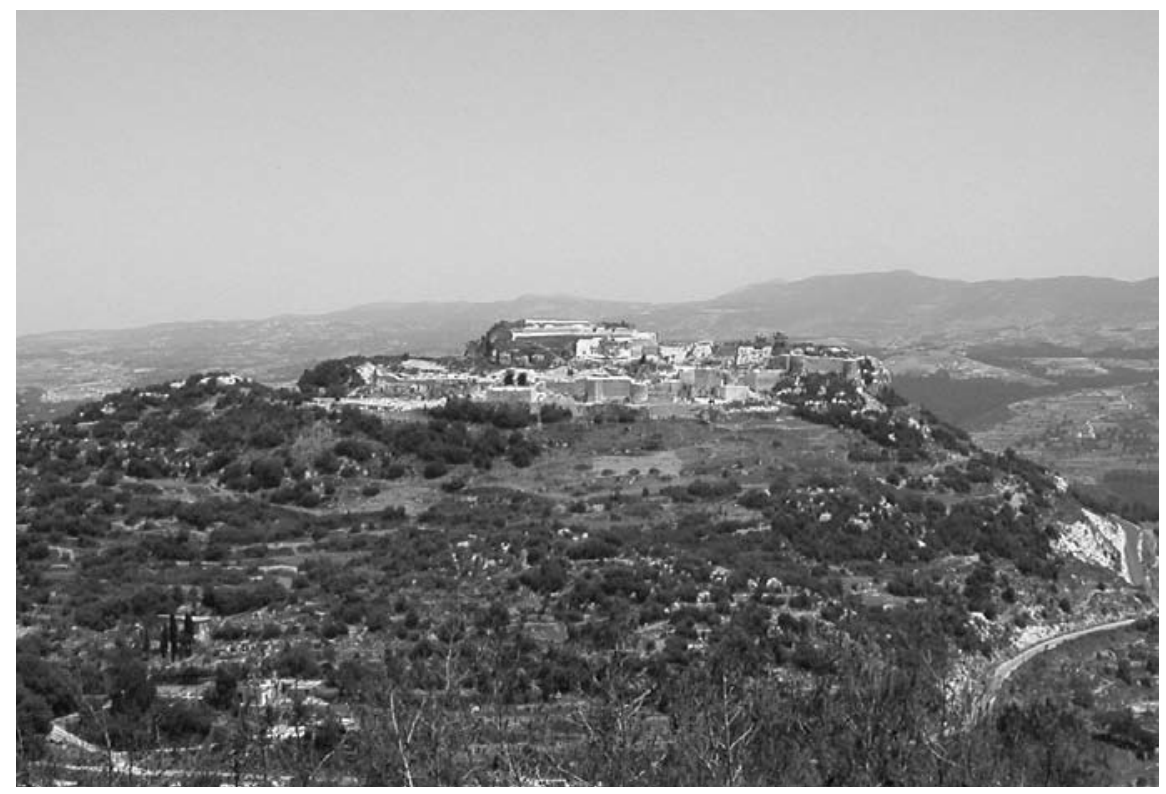

Fig. 2. Le site de Balāṭunus, vue du sud-ouest (J. Aliquot, 2008)

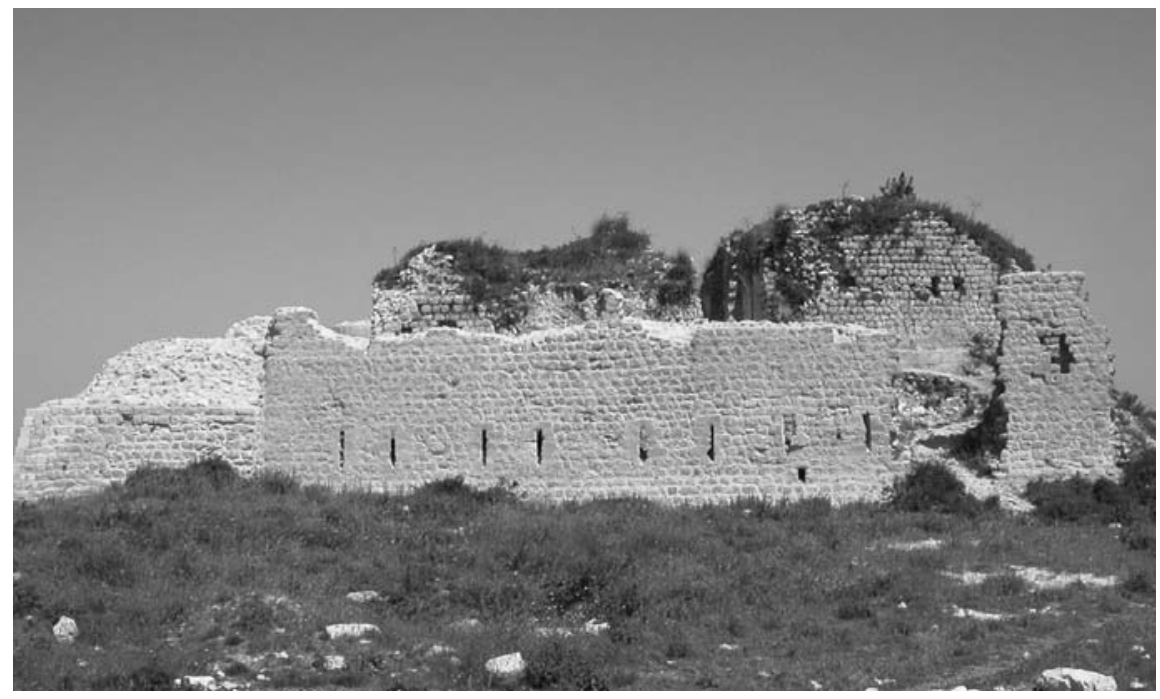

Fig. 3. Le kastron byzantin (J. Aliquot, 2008) 
pu retomber aux mains d'une tribu locale, peut-être à la faveur de la conquête de la Syrie du Nord par les Seldjoukides.

Le château n'est plus mentionné dans nos sources avant l'époque des Croisades. En mai 1118, Roger, le prince franc d'Antioche, l'échange avec les Banū Sulayḥa contre trois villages de la région d'Antioche pour le donner à Robert le Lépreux, seigneur de Saône (Șahyūn) ${ }^{13}$. Un compagnon de Saladin s'en empare à son tour en 1188. À l'époque ayyoubide, Balātunus appartient un temps au royaume alépin d'al-Malik al-Zāhir. L'invasion mongole favorise vers 1260 les tentatives d'indépendance d'une famille locale établie à Șahyūn. La forteresse capitule toutefois en 1269 devant le sultan Baybars, qui la fait réparer. Sous les Mamelouks, elle est le centre de l'un des six districts de la province de Tripoli, créée en 1289, en même temps qu'un relais sur la route de montagne entre Șahyūn et les châteaux ismaéliens. Avec toute la région de Lattaquié, elle relève de la même province au moins jusqu'au milieu du $15^{\mathrm{e}}$ siècle.

Ni l'époque où la forteresse de Balāțunus est tombée en ruine, ni celle où elle a perdu son nom ancien au profit de son appellation actuelle ne sont précisément connues. M. van Berchem, ne trouvant aucune mention de Mehelbé dans les sources médiévales, considérait ce nom comme moderne ${ }^{14}$. Comme nous le signale B. Paoli, l'histoire alaouite, essentiellement fondée sur la tradition orale, conserve toutefois la mémoire du changement de toponyme. Le nom Mehelbé, déformation de Mahāliba, vient du nom d'une tribu ('aš̄ira) alaouite affiliée à la confédération des Haddādīn. Ces derniers seraient venus de Sindjar, au nord de l'Irak actuel (s'il ne s'agit pas de l'agglomération syrienne homonyme située à l'est de Ma'arrat al-Nu'mān), dans le premier tiers du $13^{\mathrm{e}}$ siècle, parmi les troupes de l'émir et poète mystique Hasan b. alMakzūn al-Sinğārī (1187-1240), que les Alaouites des montagnes côtières de la Syrie avaient appelé au secours alors qu'ils étaient confrontés à la coalition

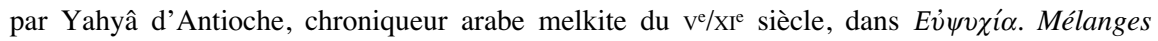
offerts à Hélène Ahrweiler, éd. M. BALARD et al., Paris 1998, p. 541-555.

13. Sur Șahyūn (le Siôn des Byzantins, Șahyūn des Arabes, aujourd'hui Qal'at Șalāḥ al-Dīn, château de Saladin), voir E. Honigmann, Historische Topographie von Nordsyrien im Altertum,

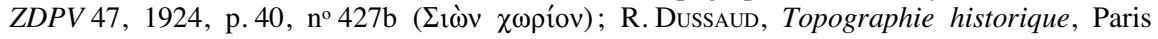
1927, p. 149-151, 187, 432; P. Deschamps, La défense du comté de Tripoli et de la principauté d'Antioche, Paris 1973, p.217-247; D. W. Morray, Sahyūn, EI 8, 1995, p.880; J.-P. FouRDRIN, Le front oriental de la forteresse byzantine de Sahyūn, CA 45, 1997, p. 51-67; IDEM, L'association de la niche et de l'archère dans les fortifications élevées en Syrie entre le $\mathrm{VI}^{\mathrm{e}}$ et le XII ${ }^{\mathrm{e}}$ siècle, Syria 75, 1998, p. 279-294; B. Michaudel et J. HAydar, Le château de Saladin (Saône/Sahyun) et son territoire (vallée du Nahr al-Kâbir al-Shamâlî): rapport des missions archéologiques syro-françaises effectuées en 2007, Chronique archéologique en Syrie 3, 2008, p. 303-317; Eidem, Le château de Saladin (Saône/Sahyun) et son territoire (vallée du Nahr alKâbir al-Shamâlî) 2008, Chronique archéologique en Syrie 4, 2010, p. 329-338; B. Michaudel, Le château de Saône/Sahyun en Syrie, creuset de l'architecture médiévale en Orient, Chronos 23, 2011, p. 67-104. L'identification de Șahyūn au site perse et hellénistique de Sigôn, souvent tenue pour acquise, est très hypothétique et ne paraît pas étayée par les fouilles récentes.

14. M. van Berchem, Inscriptions arabes de Syrie, Mémoires de l'Institut égyptien 3, 1896, p. 493. Selon le même auteur, p. 505 n. 1, les habitants de Dibāš, le village le plus proche du site, se souvenaient encore du nom ancien de Balātunus à la fin du $19^{\mathrm{e}}$ siècle. 
des Kurdes, des Turcs et des Ismaéliens ${ }^{15}$. Eux-mêmes se disent pourtant d'origine azdite, se rattachant ainsi à une grande tribu arabe préislamique, et considèrent que leur établissement dans la région côtière serait antérieur à l'arrivée des tribus sindjarites et à leur assimilation aux Haddādīn .

L'historien moderne M. Hwandah fournit les informations les plus complètes au sujet des Mahāliba ${ }^{16}$. Il délimite le territoire qui leur aurait été attribué à l'époque d'al-Makzūn al-Sinğārī et qui serait toujours le sien en donnant la liste des villages qu'ils habitent, à savoir d'est en ouest: al-Šāmiya, Stāamo, Marho, al-Barīka, al-Sindyāniyya, al-Matrakiyya, Fuwayqa, Ġayyo, al-Jadīda, al-Qāmū‘, al-Šayh Rīḥ, Tellāro, Qimmīn, Bșarrāmā, Bsīqa, Nqūro, Dayr Zayno, al-Hašḩāša, al-Fāhūra, al-Ladīne, Tarma, al-Ḥassāniyya, Bustān al-Baraka, Basțayrūn, Bḥawwāra, al-Mi'laqa, Kfarz (?), al-Qalamn, Bqaylūn, Qal'at al-Mahāliba (Balāṭunus), qui est la «capitale», 'Ayn Ǧandal, Huraybāt al-Qal'a, Dayr Wattān, al-Arrīza. Le même auteur évoque aussi les circonstances dans lesquelles Balātunus aurait été pris et rebaptisé. La citadelle était occupée par les Seldjoukides lorsque le prince Hasan al-Makzūn chassa Kurdes et Turcs et occupa toute la région, à l'exception de Balātunus, où demeurèrent les Turcs, entourés de Mahāliba au sud et à l'ouest, de 'Amāmira à l'est et au nord et de Bayt Muhammad ou Bayt al-Šilf à l'ouest. À ces occupants pré-makzūniens se seraient agrégés d'autres Turcs, immigrés de lieux non précisés. Devenus trop nombreux, ces Turcs auraient bientôt causé des problèmes, s'en prenant de plus en plus souvent aux Alaouites et volant leur bétail.

Ce n'est que sous les Ottomans, en 1643 selon M. Hwandah, que le cheikh Ġānim 'Alī (Numaylātī), de Yartī, village proche de la citadelle, aurait réuni les tribus avoisinantes pour attaquer la citadelle. Les Bayt al-Šilf, qui étaient peu nombreux (un village, Dibāš), firent appel à leurs «proches», les Rašāwina (du groupe Kalbiyya), menés par le muqaddam 'Alī Šalhūm de 'Ayn al-Kurūm, surnommé «couilles de mulet» (baydāt al-bajgl). Pris au piège, les Turcs furent alors en grande partie massacrés. Le gouvernement ottoman, bien qu'informé de l'événement, serait resté sans réaction. 'Alī Šalhūm, après la victoire, en aurait profité pour régler des conflits territoriaux entre Mahāliba et 'Amāmira, avant de repartir pour 'Ayn al-Kurūm. Les Turcs

15. Sur les tribus alaouites, leur filiation et leur répartition géographique, voir L. MAssignon, Nușairī, EI 3, 1936, p. 1030-1033, en particulier p. 1031 ; J. WeUlERSSE, Le pays des Alaouites, Tours 1940, p. 328-333; H. HALM, Nuṣayriyya, $E I^{2}$ 8, 1995, p. 148-150. L'ouvrage de base à ce sujet reste celui de M. A. Ġ. AL-ȚAwīL, Tārīh al-'alawiyȳ̄n [Histoire des Alaouites], Lattaquié 1924 (en arabe), qui compile de nombreuses sources sans jamais les citer. Sur Hasan b. alMakzūn al-Sinğārī et l'immigration sindjarite, voir aussi P. NwYIA, Makzūn al-Sinjārī, poète mystique alaouite, Studia Islamica 40, 1974, p. 87-113; B. PAOLI, La diffusion de la doctrine nuṣayrie au IV/X siècle d'après le Kitāb Hayr al-ṣañ̄'a du cheikh Husayn Mayhūb Harfūš, Arabica 58, 2011, p. 19-52, avec les références aux autres travaux alaouites.

16. À propos des Mahāliba et de leur établissement à Balātunus, tout ce qui suit est tiré de l'ouvrage de M. Hwwandah, Tārīh al-'alawiyyīn wa-ansābuhum [Histoire et généalogie des Alaouites], Beyrouth 2004, p. 214-219, dont B. Paoli a bien voulu nous traduire et nous résumer le propos. 
survivants se seraient rendus auprès du cheikh Ġānim de Yartī et l'auraient imploré de les autoriser à retourner chez eux. Il accepta, mais à condition qu'ils deviennent alaouites. Certains refusèrent et furent définitivement chassés vers les pays du Bāyir et du Būğāq et vers les villages de Burğ al-Islām (Borj Islam) et d'al-Ṣalīb (Slayeb Turkman). Ceux qui acceptèrent furent réinstallés à Yartī (familles Bandīk et al-'Āṣī) ou aux abords de la citadelle (famille al-Law'a). Quant à la citadelle, elle fut confiée aux Mahāliba car elle était sur leur territoire, et en particulier à la famille Hayr Bek qui, écrit encore M. Hwandah, «en est toujours maîtresse». C'est alors qu'elle prit le nom de Qal'at al-Mahāliba. S'il y a une chose à retenir de ces récits où l'histoire se mêle inextricablement à la légende, c'est que le site doit son nom actuel à celui d'une tribu alaouite qui s'est affirmée dans l'arrière-pays de Lattaquié entre le milieu du $13^{\mathrm{e}}$ et le milieu du $17^{\mathrm{e}}$ siècle.

Le nom ancien de Balāțunus, quant à lui, n'est guère attesté qu'en arabe, même si son étymologie est évidemment étrangère à cette langue. On admet généralement que ce toponyme recouvre le grec $\Pi \lambda \alpha \dot{\alpha} \alpha v_{0}$ os ou le latin Platanus. Seul E. Honigmann estime que la forme alternative Aflațūnus, chez

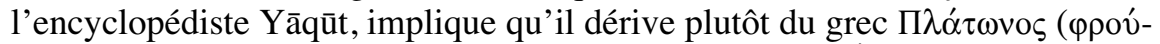
prov, $\chi \omega \rho$ íov), car Aflațūn est le nom arabe de Platon ${ }^{17}$. À ses yeux, il s'agit probablement moins d'une référence au célèbre philosophe grec tenu au Moyen Âge pour un faiseur de miracles, selon la suggestion d'H. Grégoire, que d'une confusion avec le nom de la petite cité de Paltos, certains auteurs arabes tenant à tort Balāțunus pour une ville côtière, de même qu'ils confondent Qadmous et Balanée (Banyas). On pourrait aussi supposer, si cette conjecture était vérifiable, que le site a reçu le nom d'un grand propriétaire dès l'Antiquité, à l'image de nombreux établissements ruraux de la Syrie du Nord. Cependant, il semble plus vraisemblable de considérer le toponyme

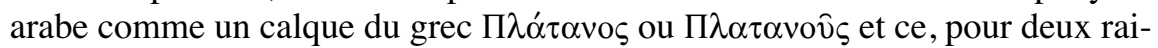
sons. Premièrement, les noms géographiques antiques tirés des noms grecs du platane ( $\pi \lambda \alpha \tau \alpha \dot{v} v 1 \sigma \tau o \varsigma, \pi \lambda \alpha ́ \tau \alpha \nu \circ \varsigma)$ sont fréquents dans toute la Méditerranée

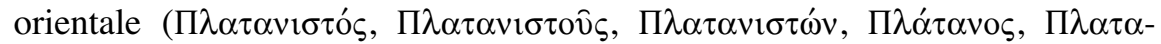

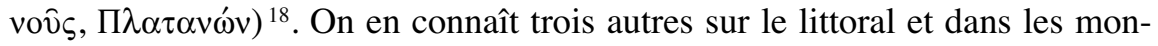

17. E. Honigmann, Die Ostgrenze, Bruxelles 1935, p. 113 n. 1, d'après YĀQūT, Mu'ğam albuldān, éd. F. WüstenfELd, I, Leipzig 1866, p. 331; IDEM, Mārașid [Abrégé], éd. T. W. G. Juynboll, I, Leyde 1852, p. 81, décrivant un grand château très élevé qu'il situe dans la partie occidentale de la principauté ayyoubide d'Alep. M. vAN BERCHEM, Inscriptions arabes de Syrie, Mémoires de l'Institut égyptien 3, 1896, p. 516, tout en relevant que les deux passages sont corrompus et ne renvoient pas aux entrées Balātunus du Mu'ğam, I, p. 710, et du Mārașid, I, p. 168, suppose que Yāqūt, en puisant à deux sources différentes, a dédoublé ses notices par erreur.

18. Outre les références reportées dans les trois notes suivantes, voir par exemple F. BöltE,

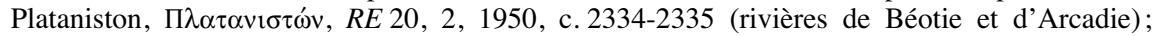

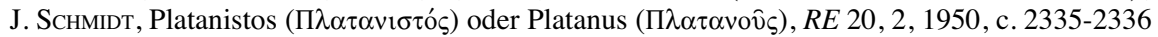

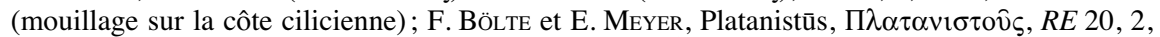
1950, c. 2336-2337 (rivière de Laconie, localité d'Élide, cap nord de l'île de Cythère); F. B. Poljakov, Die Inschriften von Tralleis und Nysa. I, Die Inschriften von Tralleis, Bonn 1989, p. 202-208, n² 250, ici p. 204, réédité par P. Thonemann, Estates and the Land of Late 
tagnes côtières du Proche-Orient, correspondant respectivement au nom d'une étape routière sur le col du Baylan, vers les Portes syriennes, entre Antioche et la Cilicie ${ }^{19}$, à celui d'une localité indéterminée entre Antioche et Laodicée $^{20}$, et à celui d'un village de Phénicie localisé à Aramoun, entre Béryte et Sidon ${ }^{21}$. Deuxièmement, la confusion phonétique entre $a$ et $o$ est si banale en Syrie que le glissement du grec $\Pi \lambda \alpha \dot{\alpha} \alpha v_{\nu} \varsigma$ ou $\Pi \lambda \alpha \tau \alpha v o \hat{\varsigma} \varsigma$ vers l'arabe Balāțunus n'aurait rien de surprenant. Il est donc fort possible que le site de Balāțunus ait reçu lui aussi l'un de ces deux noms soit dès l'Antiquité, soit au Moyen Âge à l'époque de la Reconquête byzantine.

Notre inscription commémore la prise et la fortification de Balātunus par les Byzantins. Aujourd'hui conservée au musée archéologique de Lattaquié,

Roman Asia Minor, Chiron 37, 2007, p. 443-463, col. II, 35 (غ่v $\alpha \gamma \gamma(\hat{\omega}) \Pi \lambda \alpha \tau \dot{\alpha} v \omega$, dans un registre fiscal du début du $4^{\mathrm{e}}$ siècle).

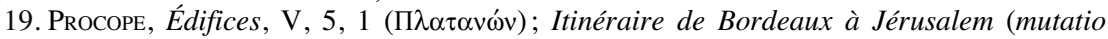
Pictanus, var. Platanus); Théophane le Confesseur, Chronique, éd. C. De Boor, Leipzig 1883-

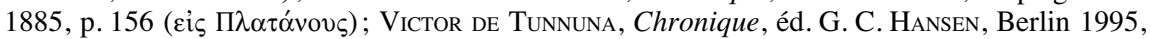
p. 141 (in possessionem Platani vocabulo). Voir E. HonigMAnN, Historische Topographie von Nordsyrien im Altertum, ZDPV 47, 1924, p. 32, $\mathrm{n}^{\text {os }} 374$ et 376; R. Dussaud, Topographie historique, Paris 1927, p. 434 et 444.

20. Il s'agit du site que l'Itinéraire Antonin (Platanos) et l'Itinéraire de Bordeaux à Jérusalem (mansio Platanus) situent respectivement à 25 et à 24 miles d'Antioche, sur la route menant de cette ville à Laodicée. M. van Berchem, Inscriptions arabes de Syrie, Mémoires de l'Institut égyptien 3, 1896, p. 493 n. 1, montre que cette étape plus proche d'Antioche que de Laodicée ne peut pas être Balāțunus. Comme le rappelle B. SPULER, П $\lambda$ ót $\alpha$ vos (2), RE 20, 2, 1950, c. 2338, le site est diversement localisé: E. Honigmann, Historische Topographie von Nordsyrien im Altertum, ZDPV 47, 1924, p. 32, n 375, le place à Ordou (en turc Yayladağı), sur la route qui contourne le flanc oriental du Casius, R. Dussaud, Topographie historique, Paris 1927 , p. 155, beaucoup plus à l'est, à Derkouch, sur le cours de l'Oronte, près d'Idlib. On peut se demander s'il ne correspond pas au site du monastère des Platanes (dylbyn, en syriaque), mentionné dans une liste de couvents et de villages du $6^{6}$ siècle et localisé tantôt dans la vallée de l'Oronte, tantôt dans les montagnes voisines. Cf. l'état de la question par A. CAQuOT, Les couvents du Massif calcaire dans quatre lettres monophysites du vie siècle, dans G. TCHALENKo, Villages antiques de la Syrie du Nord, III, Paris 1958, p. 78-79, avec les différentes localisations proposées, Dilbiyé, Kafr Dilba ou Dibbin selon E. Littmann, Idlib selon G. Tchalenko; M. Mundell Mango, Where Was Beth Zagba?, dans Okeanos. Essays presented to Ihor Ševčenko for his Sixtieth Birthday by his Colleagues and Students, éd. C. Mango, O. PritsaK et U. M. PASICZNYK, Cambridge 1983, p. 405-430, ici p. 416 et 419, ne rappelle que cette dernière hypothèse. Comme nous le suggère P.-L. Gatier, il y aurait également lieu de rapprocher son nom de celui de $[\Pi \lambda] \alpha \tau$ óvov (peut-être pour $\Pi \lambda \alpha \tau \tau^{\alpha} v o v$, non interprété jusqu'à présent), sur la mosaïque du bas-côté nord de l'église E 5 d'al-Bāra (en Apamène septentrionale, dans le Jabal Zawiyé), qui porte par ailleurs la représentation d'une autre église dédiée à saint Étienne. Voir J.-P. FourdRIN, Église E.5 d'El Bāra, Syria 69, 1992, p. 171-210, ici p. 187, fig. 3 et 18 (D. FeIsSel, Bulletin épigraphique, REG 106, 1993, p. 559, nº 624; IDEM, Chroniques d'épigraphie byzantine 1987-2004, Paris 2006, p. 199, $\mathrm{n}^{\circ} 633$ ).

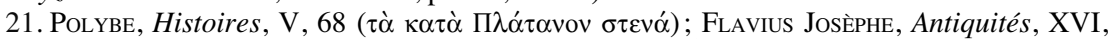

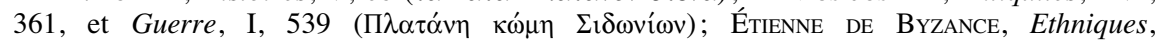

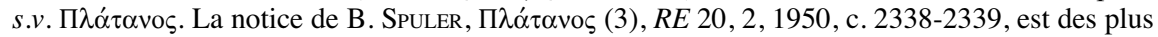
confuses. R. Dussaud, Topographie historique, Paris 1927, p. 45-47, localise le site sur la côte libanaise à Aaramoun, dont le nom évoque celui du platane en hébreu. Cette proposition est préférable à celle de C. Clermont-Ganneau, Platanos de Phénicie, dans Recueil d'archéologie orientale, VI, Paris 1905, p.65-73 (suivi par E. HonigmanN, Historische Topographie von Nordsyrien im Altertum, $Z D P V 47,1924$, p. 32, n $375 \mathrm{a})$, qui place Platanos à Eulmane (Aalamoun). 
elle a été découverte au sommet de la citadelle byzantine en 2008, à l'occasion de dégagements effectués en vue de la restauration de l'ensemble architectural. Elle est gravée en grec et en géorgien sur un grand linteau taillé dans le calcaire crayeux blanc local. Le bloc est brisé en trois fragments. Incomplet à gauche, il mesure dans son état actuel $57 \mathrm{~cm}$ de haut, $162 \mathrm{~cm}$ de large et $21 \mathrm{~cm}$ d'épaisseur. La gravure de l'inscription est profonde et soignée. Les lettres grecques ont une hauteur de 5 à $6 \mathrm{~cm}$, contre $5 \mathrm{~cm}$ pour les lettres géorgiennes. À gauche, dans la partie grecque, la restitution évidente de la cinquième ligne fixe la longueur de la lacune à plus ou moins douze caractères. La grande croix gravée en dessous dans la partie géorgienne se trouve ainsi à peu près au milieu de la pierre.

Le texte grec est le plus développé. Nous sommes redevables à D. Feissel d'avoir compris qu'il se divise lui-même en deux parties: une partie métrique de cinq dodécasyllabes aux lignes 1 à 3 ; une partie en prose aux lignes 4 à 6 , dont le texte géorgien se veut la traduction. Trois indices corroborent l'analyse métrique de la première partie: la présence d'une ponctuation aux lignes 2 et 3

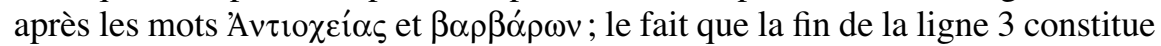

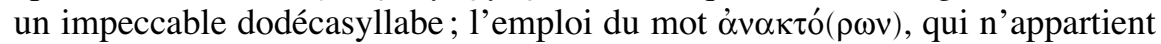
pas à la prose. La lecture proposée est conforme au schéma d'un vers de douze syllabes comportant une césure après la cinquième ou la septième syllabe et un accent sur la pénultième. Elle tient également compte de la longueur de la lacune à gauche et de la titulature du duc d'Antioche Nicétas, dont le nom est attendu

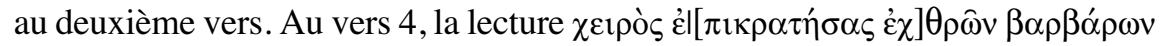
est matériellement possible, mais cette expression qui pourrait signifier «ayant

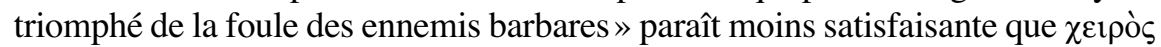
$\dot{\varepsilon} \mid[\xi \alpha \rho \pi \alpha ́ \sigma \alpha \varsigma \tau \hat{\omega} v \dot{\varepsilon} \chi] \theta \rho \hat{\omega} v \beta \alpha \rho \beta \alpha ́ \rho \omega v$.

Bien qu'une ponctuation suive le nom $T \eta \pi \varepsilon \lambda_{1}$ à la ligne 5, la seconde partie du texte grec n'est manifestement pas versifiée. L'inscription géorgienne permet ensuite de retrouver la mention des cinq forteresses érigées par le stratège de Laodicée. La date finale présente des abréviations usuelles, ainsi que des traits au-dessus des chiffres et des nombres. Nous restituons une formule bien attestée dans les inscriptions datées selon l'ère mondiale byzantine.

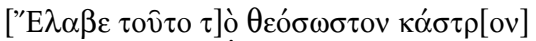

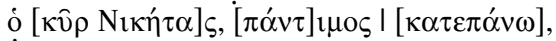

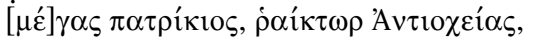
$\chi \varepsilon i \rho \varsigma_{\zeta} \dot{\varepsilon} \mid[\xi \alpha \rho \pi \alpha \dot{\alpha} \sigma \alpha \varsigma \tau \hat{\omega} v \dot{\varepsilon} \chi] \theta \rho \hat{\omega} v \beta \alpha \rho \beta \alpha \dot{\alpha} \rho \omega v$

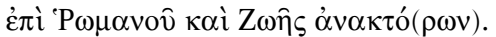

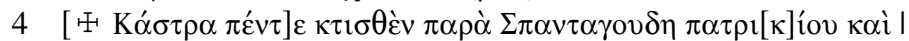

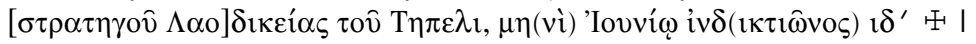

$\left[\varepsilon^{\prime} \tau(\varepsilon \imath) \dot{\alpha} \pi \mathrm{ò} \kappa \tau(\right.$ í $\left.\sigma \varepsilon \omega \varsigma) \kappa o ́ \sigma \mu(o v), \varsigma \varphi\right] \lambda \theta^{\prime}$.

Il a pris ce kastron que Dieu sauvegarde, le seigneur Nicétas, très honorable catépan, grand patrice, recteur d'Antioche, en l'arrachant des mains des ennemis barbares sous Romain et Zoé, les souverains.

Cinq kastra ont été construits par Spantagoudès Tèpeli, patrice et stratège de Laodicée, au mois de juin, indiction 14, l'an 6539 depuis la création du monde. 


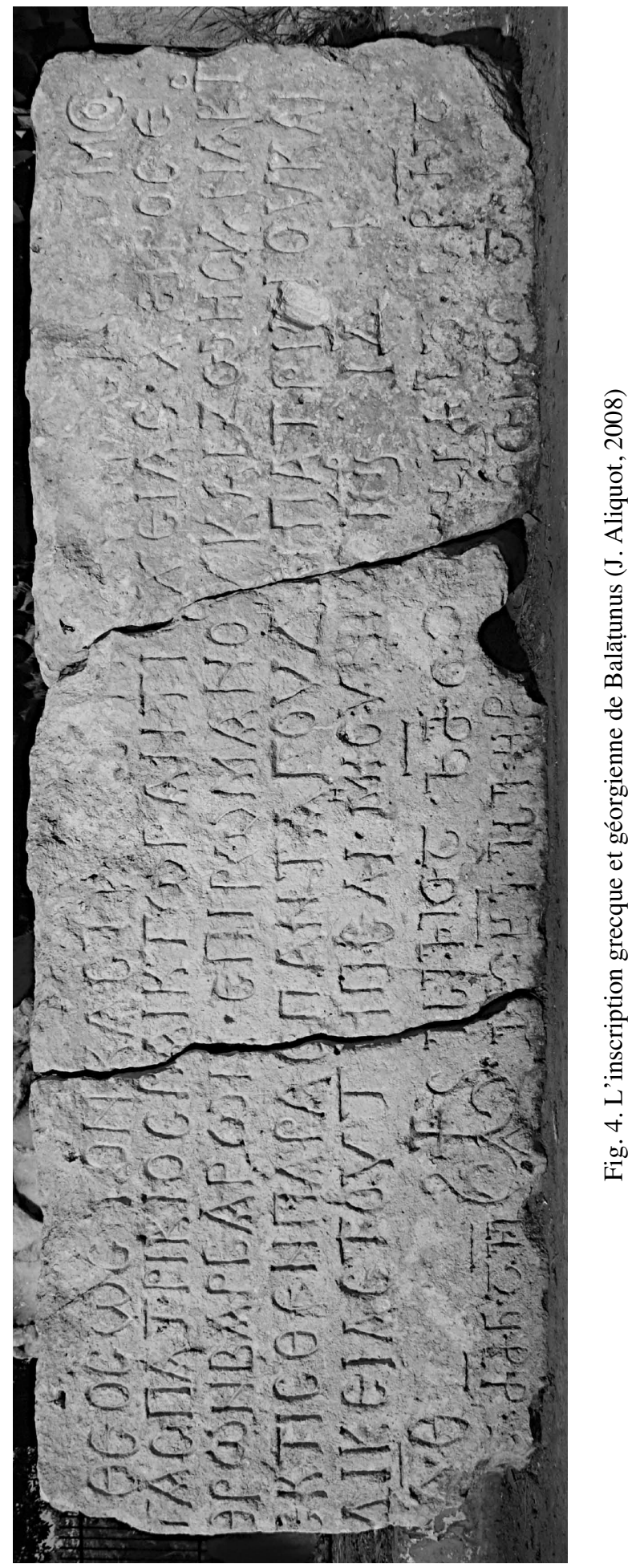


La partie géorgienne de l'inscription est ajoutée immédiatement à la suite de la grecque. Elle est gravée dans les belles capitales arrondies de l'alphabet asomtavruli. Sa facture trahit la main d'un lapicide expérimenté du $11^{\mathrm{e}}$ siècle et peut-être venu de la région d'Antioche, où d'autres documents géorgiens sont connus. Selon l'habitude du temps, le texte comporte de très nombreuses abréviations signalées par des tildes au-dessus des lettres. Ses mots sont séparés par des points. La première ligne, dont les dix-neuf caractères sont tous conservés, est gravée à droite de la croix à la suite de la date du grec. La seconde ligne, très lacunaire à gauche, ne présente plus actuellement que les traces de sept caractères à gauche et dix-sept caractères à droite de la croix. Il est possible de restituer de part et d'autre de ce motif entre vingt et trente lettres. À moins de supposer qu'elle se poursuivait sur un bloc disposé en dessous du nôtre, ce qui ne semble pas nécessaire, on peut donc considérer que l'inscription contient un texte plus court et réparti sur deux lignes, qui résume et complète la fin du grec tout en omettant de mentionner le rôle du duc d'Antioche, le nom des souverains régnants et la date. La lecture proposée cidessous tient compte du contenu de la partie grecque, des normes de l'épigraphie géorgienne et des données historiques connues pour restituer les titres, le nom et le patronyme du stratège géorgien de Laodicée. La restitution de la ligne 2 est un peu longue par rapport à la taille de la lacune, mais elle correspond au grec. Une solution pourrait être de considérer que la titulature du stratège était partiellement ou totalement omise.

1 世 ese v(i)ta z(e)moy b(e)rdz(u)l(a)d sc'(e)ria,

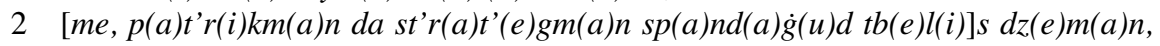
$a v(a g) e$ \& e c(i)xe ese šs (e)c'[(e)vn(i)ta gmr]t(i)sa(y)ta.

Comme il est écrit ci-dessus, moi, le patrice et stratège Spandaghud fils de Tbeli, j'ai construit ces cinq forteresses avec l'aide de Dieu.

La partie grecque du texte est exactement datée du mois de juin 1031 (en utilisant l'ère mondiale byzantine, qui prend pour point de départ la date supposée de la Création selon le récit de la Bible en 5509 av. J.-C.) ${ }^{22}$. Cette indication chronologique, apparemment absente de la version géorgienne, concerne moins la prise de Balātunus que la reconstruction de cinq forteresses sous l'autorité du stratège de Laodicée. Elle invite à relire la relation de Yahyā b. Sa'īd d'Antioche, qu'elle corrobore de manière remarquable. Dans les années 1020, selon Yahyā, les Byzantins s'appuient sur le potentat arabe local Nașr b. Mušarraf pour tenter d'asseoir leur domination sur le nord de la chaîne côtière de la Syrie. Également connu de Skylitzès, qui le désigne comme un Arabe ('A $\rho \alpha \psi)$ et le nomme toujours par son patronyme

22. V. Grumel, La chronologie (Traité d'études byzantines 1), Paris 1958, p. 220. L'usage de ce comput est attesté en 1043 dans l'épitaphe de Jean, dignitaire de l'Église de Gabala. Il a paru moins assuré dans l'épitaphe du moine Nicodème, dont l'interprétation doit sans doute être corrigée. Voir infra, Appendice, $\mathrm{n}^{\text {os }}$ 24-25. 
$(\text { Movoó } \rho \alpha \varphi)^{23}$, le personnage est mentionné sur un sceau byzantin dont le droit est orné du buste de saint Georges et dont le revers porte une légende en arabe coufique révélant que l'empereur lui avait conféré la dignité de patrice ${ }^{24}$. On comprend pourquoi: «Nașr b. Mušarraf al-Rawādīfī, écrit Yaḥyā, s'était rendu maître de tous les musulmans habitant le Ğabal alRawādīf [le nord de la chaîne côtière] et (les territoires) limitrophes qui étaient aux mains des Rūm, ainsi que des villages situés dans cette montagne, et sa position était puissante ${ }^{25}$.

Ses revirements épisodiques ont valu à Nașr b. Mušarraf d'être incarcéré par deux fois à Antioche. L'homme fort de la montagne a cependant trouvé un protecteur en la personne du catépan Michel Spondylès (1026-1029), qui lui a confié par un édit la construction de la forteresse d'al-Manīqa afin de défendre le territoire byzantin face à l'émir fatimide de Tripoli ${ }^{26}$. En 1030, après la destitution de Spondylès, Nașr refuse de remettre al-Manīqa au duc Constantin Karantènos et entreprend d'édifier une deuxième forteresse à Bikisrā'îl (récemment rebaptisée Qal'at Ban̄̄ Qaḥțān), sur le chemin le plus court, mais non le plus facile, entre Gabala et la vallée de l'Oronte. Les Byzantins décident alors de l'écarter définitivement et d'achever eux-mêmes la construction du château, qu'ils nomment sans doute Argyrokastron. Ils y postent un commandant que Yahyyā considère comme un incapable et Naṣr b. Mušarraf parvient à s'emparer de Bikisrā'īl par une ruse ${ }^{27}$. Dans le même

23. Jean Skylitzès, Synopsis historiarum, éd. I. Thurn, Berlin et New York 1973, p. 379 et 383, trad. B. Flusin et J.-C. Cheynet, Paris 2003, p. 314-315 et 317-318.

24. J.-C. Cheynet, C. Morrisson et W. SeibT, Les sceaux byzantins de la collection Henri Seyrig, Paris 1991, p. 251, no 395 (al-bațrīq Nașr b. Mušarraf). Des personnages vraisemblablement apparentés à Nașr b. Mušarraf sont au service de Byzance aux $11^{\mathrm{e}}$ et $12^{\mathrm{e}}$ siècles. Voir Ch. Stavrakos, Korrekturen zur Lesung einiger Siegel des Numismatischen Museums Athen, dans Studies in Byzantine Sigillography 2, éd. N. OIKONOMIDEs, Washington 1990, p. 39-47, ici p. 42-44; A.-K. Wassiliou et W. SeIBT, Die byzantinischen Bleisiegel in Österreich. II, Zentralund Provinzialverwaltung, Vienne 2004, p. 259-260; J.-C. CHEYNET, L'apport arabe à l'aristocratie byzantine des $\mathrm{X}^{\mathrm{e}}-\mathrm{XI}^{\mathrm{e}}$ siècles, $B S 56,1995$, p. 143, repris et complété dans La société byzantine. L'apport des sceaux, Paris 2008, p. 634-636.

25. YAHYĀ, Histoire, III, p. 500-501 [132-133].

26. YaHYĀ, Histoire, III, p. 502-503 [134-135]; JEAn Skylitzès, Synopsis historiarum, éd. I. Thurn, Berlin et New York 1973, p. 379, trad. B. Fuusin et J.-C. CheYnet, Paris 2003, p. 314-315; AL-'Az̄ìīi, Ta'rīh Halab [Histoire d'Alep], éd. I. ZAHRÛR, Damas 1984, p. 329 (année 421). Sur la forteresse d'al-Manīqa (Menikos des Byzantins, Malaicas ou castellum Malavans des Latins, aujourd'hui Qal'at Qsabiyé), voir P. Deschamps, La défense du comté de Tripoli et de la principauté d'Antioche, Paris 1973, p. 335-336.

27. YануĀ, Histoire, III, p. 504-505 [136-137]. Sur le château (castellum Vetulae, La Vieille des Latins, Qal 'at Banī Isrā'̄il), voir P. Deschamps, La défense du comté de Tripoli et de la principauté d'Antioche, Paris 1973, p. 337-338. Il s'agit de l'Argyrokastron des Byzantins selon F. Micheau et G. Troupeau, dans Yahyā, Histoire, III, p. 526-527 n. 41 [158-159]: «Skylitzès, 383, rapporte, après la prise d'al-Manīqa, qu'une autre forteresse appelée Argyrokastron, "construite sur un rocher escarpé", fut prise par les Byzantins. C. CAHEN, La Syrie, cité n.9, p. 172 et 173 [qui réfute la localisation d'Argyrokastron à Safita, le Chastel-Blanc des Croisés], avait refusé l'identification d'Argyrokastron avec Bikisrā'̄il, celle-ci étant située "sur une croupe ovale peu élevée", ce qui lui apparaissait en contradiction avec la description des sources byzantines. Mais le site comprend bien de profonds ravins (voir P. Deschamps, La défense, cité n. 26, p. 335). Il est donc possible de considérer qu'il n'y eut qu'une seule forteresse prise par les 
temps, «d'autres habitants de la montagne, appelés les Banū l-Aḥmar, édifièrent une autre forteresse appelée Balātunus entre Lattaquié et la ville de Barzūyah $\left(\right.$ Burzay $\left.^{28}\right)$ ». La citadelle fait partie d'un réseau de places fortes aménagées et tenues par les tribus locales: «D’autres habitants (de la montagne) appelés Banū Ġannāğ construisirent également une forteresse. Un autre (membre) de leur tribu, appelé Ibn al-Kāšiḥ, les imita et construisit également une autre forteresse. Il y eut ainsi cinq forteresses qui se renforçaient les unes les autres. Ils se rendirent maîtres de toute la montagne et des territoires limitrophes. Tous furent d'accord pour se diriger vers les districts des Rūm qui leur étaient voisins et y faire des incursions. Leur position devint sérieuse ${ }^{29}$. De son côté, Mušarraf recueille les faveurs du calife fatimide alZāhir (1021-1036) et menace d'autres positions byzantines, de Tripoli à Alep.

La lecture de Yahyā impose l'idée que les montagnes côtières de la Syrie constituent au début du $11^{\mathrm{e}}$ siècle un monde plein, islamisé et hostile aux ingérences extérieures ainsi qu'à toute tentative d'appropriation des ressources locales ${ }^{30}$. Au sujet des chefs qui tiennent le haut du pavé au sein de la société tribale, C. Cahen suggère qu'ils sont «pour une bonne part des Nușayris » et que «la première manifestation publique du nușayrisme dans cette région est l'activité de Nașr b. Mušraf [i.e. Nașr b. Mušarraf]» ${ }^{31}$. L'hypothèse est séduisante, même si rien ne garantit l'adhésion des monta-

Byzantins après al-Manīqa, appelée Bikisrā’̄̄l chez Yạ̣yā, Argyrokastron chez Skylitzès.» Dans leur traduction annotée de JEAn SkyLitzès, Empereurs de Constantinople, Paris 2003, p. 318 et n. 45, B. Flusin et J.-C. CheYNEt localisent Argyrokastron à al-'Ullayqa, suivant l'avis de C. Cahen et de P. Deschamps (cf. déjà E. Honigmann, Die Ostgrenze, Bruxelles 1935, p. 114 n. 5, dubitatif), et traduisent le nom de la forteresse par "Château-d'argent», ce qui est correct sur le plan linguistique, mais ne rend pas compte de l'éventuelle connotation honorifique et dynastique du toponyme, que souligne G. Schlumberger, L'épopée byzantine, III, Paris 1905, p. 92.

28. Sur Burzay (Barzūyah, Borzé, Qal'at Berzé, Qal'at Merzé), voir E. Honigmann, Historische Topographie von Nordsyrien im Altertum, ZDPV 46, 1923, p. 173, no 116b (Bopל̌́) ; R. Dussaud, Topographie historique, Paris 1927, p. 152-154, 162, 187, 197, 432; J. Sourdel-Thomine, Barzūya, $E I^{2}$ 1, 1960, p. 1105; P. Deschamps, La défense du comté de Tripoli et de la principauté d'Antioche, Paris 1973, p. 345-348; J. Mesqui, Bourzeÿ, une forteresse anonyme de l'Oronte, dans La fortification au temps des Croisades, éd. N. FaucherRe, J. Mesqui et N. Prouteau, Rennes 2004, p. 95-133.

29. YАHYĀ, Histoire, III, p. 504-507 [136-139].

30. Les prospections archéologiques en cours, en particulier celle de la vallée du Nahr elKébir du Nord, que B. Michaudel et J. Haydar dirigent, confirment l'occupation de la région au Moyen Âge, tout en mettant en cause l'idée, notamment défendue par X. DE PLANHol, Minorités en Islam, Paris 1997, p. 84, que les tribus se seraient réfugiées dans une montagne quasiment vide d'hommes au $11^{\mathrm{e}}$ siècle. Voir B. Michaudel et J. Haydar, Le château de Saladin (Saône/Sahyun) et son territoire (vallée du Nahr al-Kâbir al-Shamâlî): rapport des missions archéologiques syro-françaises effectuées en 2007, Chronique archéologique en Syrie 3, 2008, p. 316-317, et EIDEM, Le château de Saladin (Saône/Sahyun) et son territoire (vallée du Nahr alKâbir al-Shamâlî) 2008, Chronique archéologique en Syrie 4, 2010, p. 337-338, pour une présentation du projet.

31. C. CAHEN, Note sur les origines de la communauté syrienne des Nuṣayris, Revue des études islamiques 38, 1970, p. 243-249. 
gnards et de leurs maîtres à la doctrine religieuse nușayrie (alaouite) ${ }^{32}$. Ce qui est plus certain, c'est que la collusion entre les tribus représente un danger assez grave pour que Nicétas, le nouveau duc d'Antioche, intervienne en personne. Au début du printemps de 1031, profitant de la trêve entre l'empereur byzantin et le Mirdasite Nașr b. Șāliḥ, maître d'Alep, «le recteur et catépan d'Antioche Nicétas s'efforça d'arranger l'affaire de Nașr b. Mušarraf, des Banū l-Aḥmar et des Banū Gannāğ, et d'obtenir leur retour à l'obéissance ainsi que la livraison des forteresses qui étaient entre leurs mains ». Les pourparlers échouent. «Il assiégea la forteresse de Balāṭunus dont Ibn al-Aḥmar avait entrepris la construction et il en commença l'attaque. Mais Ibn alAhmar la lui remit contre la sauvegarde que lui et tous ceux qui étaient dans la forteresse pourraient partir vers le territoire des musulmans. Nicétas accepta et prit possession de la forteresse. Il renvoya avec Ibn al-Aḥmar des gens qui le conduisirent en lieu sûr. Il mit dans la forteresse des hommes et des équipements; il prescrivit à la garnison d'en accroître les défenses et d'achever les constructions nécessaires ${ }^{33}$. Selon Yahyyā, les deux places fortes (non localisées) des Banū Ġannāğ sont détruites après que leurs occupants les ont remises au duc d'Antioche dans les mêmes conditions que celle de Balātunus.

La partie grecque de notre inscription rappelle les titres et la fonction des personnages impliqués dans la prise et la construction du kastron byzantin de Balātunus. Les membres du couple impérial Romain III Argyre et Zoé sont dénommés au moyen du terme poétique archaïsant óvók

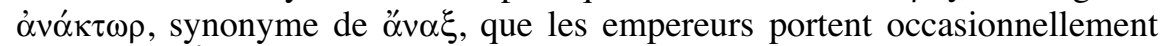
au Moyen Âge ${ }^{34}$. Le duc d'Antioche Nicétas leur est normalement subor-

32. Voir Th. Bianquis, Damas et la Syrie sous la domination des Fatimides, Damas 19861989, p. 480-481 n. 2: «Rien, dans les textes que nous avons étudiés, ne nous permet de confirmer, ni d'infirmer cette proposition». Cf. toutefois B. PAOLI, La diffusion de la doctrine nuṣayrie au $\mathrm{IV}^{\mathrm{e}} / \mathrm{X}^{\mathrm{e}}$ siècle, Arabica 58, 2011, p. 31-32, à propos de la notice biographique que le cheikh Husayn Mayhūb Harfūš (1890-1959) consacre à Abū al-Layt al-Kattān̄̄ al-Halabī dans son Kitāb hayr al-șan̄' a fì muhtașar tārīh ġulāt al-š̄' a [Le livre du meilleur des bienfaits : abrégé d'histoire des chi 'ites exagérateurs], ouvrage inédit dont une copie en quatre volumes se trouve à l'Institut français du Proche-Orient (Damas), ici vol. I, p. 156, n ${ }^{\circ} 7$ : originaire de Sarmīn, près d'Idlib, en Syrie du Nord, où il filait le lin (d'où sa nisba d'al-Kattān̄̄), Abū al-Layt al-Kattān̄̄ al-Halabī, disciple syrien de la communauté alaouite, «initia huit hommes avec qui il se rendit à la Mecque, où il demeura une année, puis revint avec eux dans la montagne à l'ouest de Hamāt

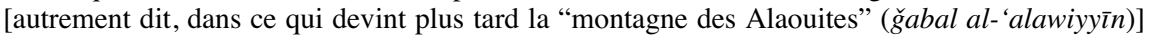
pour s'y installer; et tous eurent une descendance, tant exotérique qu'ésotérique». Comme l'écrit B. Paoli (p. 32), à qui nous empruntons la traduction précédente, «malgré son peu de précision, cette information est très précieuse: elle témoigne de ce que, dès la seconde moitié du $\mathrm{IV} / \mathrm{X}^{\mathrm{e}}$ siècle, et donc bien avant qu'Abū Sa'īd al-Ṭabarān̄̄, successeur d'al-Ǧillī à la tête de la branche syrienne de la communauté, ne quitte Alep pour s'installer à Lattaquié [au début du $11^{\mathrm{e}}$ siècle], des Alaouites s'étaient déjà établis dans les montagnes côtières de Syrie».

33. YануĀ, Histoire, III, p. 508-511 [140-143].

34. Livre des cérémonies, éd. J. H. Leich, J. J. Reiske et B. G. Niebuhr, Bonn 1829, p. 198, 253, 267, 279, 281, 333, 434-435, 437-438 (10 siècle); Constantin Porphyrogénète, De

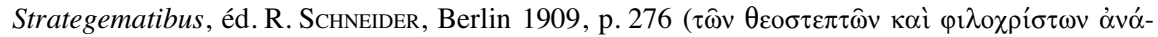
$\kappa \tau \omega v$ 'P $\omega \mu \eta \zeta)$; D. Feissel et A. PhiLipPidis-BraAt, Inventaires en vue d'un recueil des inscriptions historiques de Byzance. III, Inscriptions du Péloponnèse (à l'exception de Mistra), TM 9, 
donné. Il est crédité, assez abusivement vu les tractations qu'évoque Yahyyā, de la prise du château face aux ennemis barbares, c'est-à-dire les Banū lAḥmar, qui avaient commencé à mettre le site en valeur. Il s'agit d'un personnage connu, à ne pas confondre avec son successeur homonyme, frère de l'empereur Michel IV le Paphlagonien (1034) ${ }^{35}$. Notre homme est originaire de Mistheia en Lycaonie ${ }^{36}$. Eunuque et patrice, vraisemblablement identifiable au Nicétas de Pisidie envoyé par Constantin VIII en Orient avec la charge de duc d'Ibérie vers 1027, comme on le verra plus loin, le vainqueur des Banū 1-Aḥmar a exercé la fonction de recteur et catépan (duc) d'Antioche de 1030 à 1032. Sa titulature est conforme à celle du sceau qui le donne pour patrice, recteur et catépan de la Grande Antioche ${ }^{37}$. L'emphase qui entoure l'énumération de ces charges et de ces dignités rappelle l'importance cruciale du duc d'Antioche, qui occupe la seconde place dans la hiérarchie des fonctions militaires de l'Empire, après le domestique des Scholes.

Deux expressions sont remarquables dans la titulature de Nicétas, comme nous le fait observer J.-C. Cheynet, à qui nous devons les remarques suivantes. La dignité de grand patrice, restituée dans notre inscription pour des raisons métriques, est inconnue à Byzance. Elle peut s'expliquer par une licence poétique autant que par une imitation de formules du type $\mu \varepsilon^{\prime} \gamma \alpha \varsigma \beta \alpha \sigma$ -

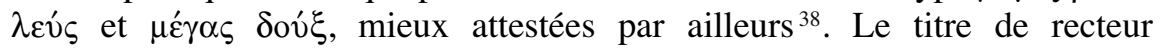
d'Antioche, parfaitement lisible sur la pierre, est lui aussi inédit et surprenant.

1985, p. 299-300, n 41, pl. 8, 1 (dédicace d'une tour de signalisation du Péloponnèse sous un empereur Léon, ơv $\alpha \xi \Lambda \varepsilon ́ \omega v$, Léon V, 813-820, ou Léon VI, 886-912), réédité par A. GuILLOU, Recueil des inscriptions grecques médiévales d'Italie, Rome 1996, p. 39-40, n 43 (qui opte pour Léon VI); A. Guillou, Un document sur le gouvernement de la province. L'inscription historique en vers de Bari (1011), dans IDEM, Studies on Byzantine Italy, Londres 1970, article

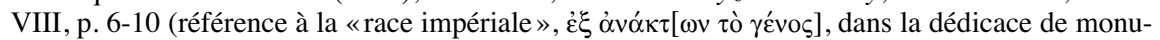
ments publics au nom du catépan Basile Mésardonitès, en 1011).

35. Pour la liste des ducs ou catépans d'Antioche, voir J.-C. CHEYnet, Sceaux de la collection Zacos (Bibliothèque nationale de France) se rapportant aux provinces orientales de l'Empire byzantin, Paris 2001, p. 22-23; IDEM, The Duchy of Antioch during the Second Period of Byzantine Rule, dans East and West in the Medieval Eastern Mediterranean, I, éd. K. N. Ciggaar et D. M. Metcalf, Louvain 2006, p. 3 n. 10; Idem, Les ducs d'Antioche sous Michel IV et Constantin IX, dans Novum Millenium. Studies on Byzantine History and Culture dedicated to Paul Speck, éd. C. SodE et S. TAKÁcs, Aldershot 2001, p. 52-63, repris et complété dans La société byzantine. L'apport des sceaux, Paris 2008, p. 197-207, cf. également p. 573.

36. K. Belke et M. Restle, Galatien und Lykaonien (TIB 4), Vienne 1984, p. 205-206, s.v. Mistheia.

37. N. Oiкonomides, A Collection of Dated Byzantine Lead Seals, Washington 1986, p. 8182, no 80. Cf. YAHYĀ, Histoire, III, p. 500-501 [132-133] (eunuque, patrice, recteur d'Antioche); JeAn Skylitzès, Synopsis historiarum, éd. I. Thurn, Berlin et New York 1973, p. 382, trad. B. Flusin et J.-C. Cheynet, Paris 2003, p. 317 (originaire de Mistheia, catépan d'Antioche). Pour l'identification de Nicétas de Mistheia au duc d'Ibérie Nicétas de Pisidie, voir infra, n. 6364.

38. Sur ce point, J.-C. Cheynet nous rappelle aussi que Gagikios (Gagik), ancien roi d'Ani passé au service de Byzance, avait été nommé grand duc du Charsianon. Voir W. SEIBT, War

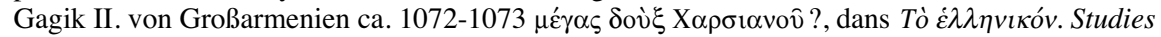
in honor of Speros Vryonis, Jr., éd. J. S. Allen, II, New Rochelle 1993, p. 159-168. On pourrait multiplier les exemples aux $11^{\mathrm{e}}$ et $12^{\mathrm{e}}$ siècles. 
En tant que dignité, il n'est habituellement suivi d'aucune indication géographique. On trouve cependant une formule comparable à propos de deux ducs d'Antioche du $11^{\mathrm{e}}$ siècle, la première dans une lettre de Philétos Synadènos à son ami Nicéphore Ouranos, «magistre d'Antioche» ${ }^{39}$, la seconde chez Skylitzès à propos du duc Ouranos, lui aussi nommé «magistre d'Antioche» par l'empereur Michel VI Stratiôtikos ${ }^{40}$. Tout se passe donc comme s'il existait au $11^{\mathrm{e}}$ siècle une tradition consistant à désigner le duc d'Antioche d'après sa dignité la plus élevée et non d'après sa fonction officielle, en privé comme en public.

Le patrice Spandaghud fils de Tbeli est le stratège qui a supervisé la construction du kastron de Balātunus. Sa mention permet d'ajouter un nom dans la très courte liste des dignitaires byzantins connus pour avoir été chargés de Laodicée, complétant ainsi ce que l'on sait de l'histoire de cette cité portuaire de la Syrie à l'époque de la Reconquête ${ }^{41}$. En 968, la ville, jusqu'alors soumise aux Hamdanides, est contrainte de verser un tribut à Nicéphore Phocas, qui laisse en place Abū l-Husayn 'Alī b. Ibrāhīm b. Yūsuf al-Fuṣayṣ, l'émir tanūhide local, avec le titre de stratège ${ }^{42}$. Elle passe peutêtre sous le contrôle des Fatimides à la suite de l'offensive égyptienne contre Antioche en 970-971. C'est du moins ce que l'on pourrait déduire du fait que le taktikon de l'Escorial, rédigé sous Jean Tzimiskès, ne porte aucune mention de son stratège ${ }^{43}$. Laodicée a dû être reprise par cet empereur en 975, au cours de la grande campagne de la dernière année de son règne. Bien que ponctuellement exposée aux assauts des Fatimides, notamment dans les années 10551057, elle reste aux mains des Byzantins pendant plus d'un siècle, avant que les Seldjoukides ne s'en emparent à leur tour, probablement en même temps

39. J. Darrouzès, Épistoliers byzantins du Xe siècle, Paris 1960, p. 254-255 ( $\tau \hat{\emptyset} \mu \alpha \gamma i \sigma \tau \rho \varphi$

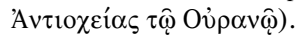

40. JeAn Skylitzès, Synopsis historiarum, éd. I. Thurn, Berlin et New York 1973, p. 483,

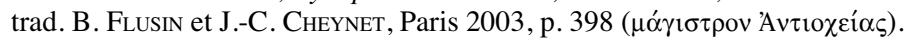

41. E. Honigmann, Laodikeia am Meere, $R E 12$, 1924, c. 713-718, ici c. 717 ; G. Wiet, Une inscription de Malik Zāhir Gāzī à Latakieh, Bulletin de l'Institut français d'archéologie orientale 30, 1931, p. 273-292; E. Honigmann, Die Ostgrenze, Bruxelles 1935, p. 94, 97, 104-106, 108-109, 122, 125, 128, 130 ; C. CAHEN, La Syrie du Nord, Paris 1940, p. 110, 165, 187-188, 208, 212, 221-223, 227-230, 233-234, 240, 243-245, 252, 260; W. Felix, Byzanz und die islamische Welt, Vienne 1981, p. 62, 92, 99, 120 ; N. ElisséEF, al-Lādhikiyya, $E I^{2}$ 5, 1986, p. 593 596; Th. Bianquis, Damas et la Syrie sous la domination des Fatimides, Damas 1986-1989, p. 18, 146, 180, 376, 565-568; J.-C. Cheynet, Sceaux de la collection Zacos, Paris 2001, p. 7577; R. Aubert, Laodicée de Syrie, DHGE 30, 2008, c. 513-517; B. PAoli, La diffusion de la doctrine nuṣayrie au IV $/ \mathrm{X}^{\mathrm{e}}$ siècle, Arabica 58, 2011, p. 43-45.

42. KamĀL aL-Dīn Ibn AL-'Adīm, Histoire d'Alep [Zubdat al-halab min ta'rīh Halab], éd. S. Dahan, I, Damas 1951, p. 158-159, relate l'établissement de la domination byzantine sur Laodicée et l'attribution de la charge de stratège à Abū al-Husayn 'Alī b. Ibrāhīm b. Yūsuf alFuṣayṣ par Nicéphore Phocas en l'an 357 de l'hégire (968). Sur les Tanūhides de Lattaquié sous les Hamdanides et sous les Byzantins, cf. B. PAol, La diffusion de la doctrine nuṣayrie au $\mathrm{IV} / \mathrm{X}^{\mathrm{e}}$ siècle, Arabica 58,2011 , p. 43-45.

43. N. OIкоNomidès, Les listes de préséance byzantines des IXe et $X^{e}$ siècles, Paris 1972, p. 355 n. 381 . 
qu'Antioche, vers 1084-1085. Lors de la première croisade, Guynemer, vassal de Baudouin de Boulogne, l'enlève aux Turcs avec ses corsaires flamands et frisons en août 1097, bien avant l'arrivée des premiers croisés en Syrie. Les Byzantins, d'abord alliés à Raymond de Saint-Gilles, la disputent dès l'année suivante aux Normands de Bohémond de Tarente, le nouveau prince d'Antioche. Ils n'en sont définitivement dépossédés par les mêmes croisés qu'en 1108.

À l'époque de la domination byzantine, les stratèges de Laodicée sont confrontés à des événements qui ont pu modifier les caractères démographiques et confessionnels de la cité. En 992, les musulmans de la ville se révoltent et le duc d'Antioche Michel Bourtzès déporte les insurgés vers d'autres régions de l'Empire ${ }^{44}$. Un peu plus tard, des chrétiens d'Égypte et de Syrie fuyant les persécutions du calife fatimide al-Hākim (996-1021) auraient trouvé refuge dans la cité, ainsi qu'à Antioche et dans d'autres villes de l'Empire byzantin ${ }^{45}$. Les premiers stratèges de Laodicée connus sont un certain Karamuruk et peut-être le protospathaire Isaac Ibèros, respectivement actifs en 980-981 et dans le dernier quart du $10^{\mathrm{e}}$ siècle ${ }^{46}$. Dans la première moitié du $11^{\mathrm{e}}$ siècle, le seul stratège de Laodicée attesté jusqu'à présent était Jean, dont les sceaux mentionnent le titre aulique de protospathaire, semblable à celui de son hypothétique prédécesseur Isaac Ibèros, mais inférieur en dignité à celui de patrice ${ }^{47}$. Cet homme a peut-être eu la charge de Laodicée avant le patrice Spandaghud plutôt qu'après lui.

L'intervention du stratège Spandaghud à Balāțunus offre aussi un aperçu intéressant sur l'organisation de l'arrière-pays de la cité à l'époque byzantine. Elle indique que, à l'intérieur du très vaste territoire confié au duc d'Antioche, le thème de Laodicée s'étend théoriquement sur tout le versant occidental de la montagne, avec ses bourgs et ses kastra, de la latitude de Gabala au sud aux premières pentes du Casius au nord. Au début du $12^{\mathrm{e}}$ siècle, dans la liste des territoires censément cédés à Bohémond de Tarente ou conservés par Alexis Comnène en vertu du traité de Déabolis (1108), Anne Comnène évoque encore le district stratégique de Laodicée, qui confine vers le nord aux districts d'Antioche, alors confiés à des fonctionnaires civils, et aux districts militaires de Gabala au sud et de Burzay à l'est ${ }^{48}$. À l'échelon inférieur se trouvent les kastra et les bourgs ruraux. En Syrie comme ailleurs dans l'Empire byzantin, le kastron n'est pas une simple citadelle, mais un

44. YAHYĀ, Histoire, II, p. 406-407 [198-199].

45. YAHYĀ, Histoire, II, p. 506 et 519 [298 et 311].

46. J.-C. Cheynet, Sceaux de la collection Zacos, Paris 2001, p. 76, d'après YAHYĀ, Histoire, II, p. 439 [231] (Karamuruk, identifiable selon J.-C. Cheynet à un certain Karmalikès connu par des sceaux inédits), et N. P. LiXAČEv, Molivdovuly Grečeskogo Vostoka [Sceaux de plomb de l'Orient grec], éd. V. S. ŠANDRovsKaJA, Moscou 1991, p. LXVI, no 9 (Isaac Ibèros).

47. J.-C. Cheynet, Sceaux de la collection Zacos, Paris 2001, p. 76-77, no 39.

48. Anne Comnène, Alexiade, XIII, 12, 18 (Antioche, Burzay) et 21 (Laodicée, Gabala). Voir K.-P. TodT, Antioch and Edessa in the So-Called Treaty of Deabolis (September 1108), Aram 11-12, 1999-2000, p. 485-501, en particulier p. 493-495. 
monument public fortifié, au centre d'un bourg et d'un territoire administratif et fiscal dirigé par un fonctionnaire de l'État ${ }^{49}$. Yahyā mentionne la présence du commandant byzantin de Balāțunus peu de temps après la prise du château. Il lui reconnaît la charge d'axiarque, probablement équivalente à celle du taxiarque, chef d'un contingent de mille hommes ${ }^{50}$.

La partie géorgienne de notre texte indique que Spandaghud a entrepris des travaux sur cinq éléments fortifiés. L'usage du démonstratif dans l'expression «ces cinq forteresses» entre à première vue en contradiction avec la commémoration de la prise du seul château de Balāțunus par le duc d'Antioche. On peut supposer qu'il renvoie à la mention de cinq citadelles dans la partie grecque de l'inscription. Cela étant admis, il est difficile de localiser ces ouvrages sur le site même, car la forteresse byzantine a été englobée dans des installations plus récentes. Seule une étude architecturale minutieuse, éventuellement associée à des fouilles archéologiques, permettra de préciser l'aspect du kastron, voire de retrouver les traces de la première installation des Banū 1-Aḥmar. La découverte du bloc inscrit au sommet de la citadelle, après une succession d'au moins cinq portes monumentales, permet de faire l'hypothèse que le stratège de Laodicée s'est attelé à renforcer les défenses de Balātunus en faisant construire les enceintes associées à ces passages. L'idée s'accorderait avec le témoignage déjà cité d'al-Dimašqī, qui caractérise la forteresse par sa succession de onze portes vers 1300, à la suite des travaux entrepris aux époques croisée, ayyoubide et mamelouke.

Une solution peut-être préférable, en raison de sa simplicité, serait de considérer que le stratège de Laodicée prévoyait en juin 1031 de construire quatre forteresses en plus de celle de Balātunus. Il pourrait s'agir des cinq citadelles que les tribus montagnardes avaient commencé à aménager juste avant l'intervention du duc Nicétas. Dans ce cas, notre texte permettrait de corriger Yahyāa qui indique explicitement que deux d'entre elles, celles des Banū Gannāğ, avaient été démantelées après la reddition de leur garnison. Même s'il fallait exclure ces deux forteresses de notre liste, on retiendra que l'Empire a tenté de contrôler systématiquement les tribus montagnardes en s'appuyant sur un réseau de places fortes. Du reste, la région ne manque guère de sites où l'on reconnaît la présence de fortifications antérieures à l'époque croisée et attribuables en tout ou partie aux Byzantins (Bikisrā'̄̂l, Burzay, al-Manīqa, Șahyūn, pour ne citer que les plus proches ${ }^{51}$ ). Toujours d'après Yahyā, la forteresse d'al-Manīqa a fait l'objet de réfections à la suite de la prise de Balātunus: après un premier échec de Nicétas, dû à la résistance des occupants et à l'arrivée de l'hiver à la fin de l'année 1031, elle est prise en même temps que des centaines de captifs le $1^{\text {er }}$ décembre 1031, puis restaurée

49. A. GuILlou, Recueil des inscriptions grecques médiévales d'Italie, Rome 1996, p. 197198.

50. YAHYĀ, Histoire, III, p. 526-527 [158-159]. Voir J.-C. CHEYNET, Note sur 1'axiarque et le taxiarque, $R E B$ 44, 1986, p. 233-235.

51. Voir supra, n. 13 (Șahyūn), 26 (al-Man̄̄qa), 27 (Bikisrā’̄il) et 28 (Burzay). 
par les Byzantins ${ }^{52}$. De même, Bikisrā'̄̄l, assiégée à deux reprises, au cours de l'hiver 1031 et pendant l'été 1032, puis finalement enlevée le 17 juillet de cette année, aurait été entièrement reconstruite à la suite de ces événements ${ }^{53}$.

En dépit des succès militaires de Nicétas et des travaux de fortification réalisés dans la montagne, il reste que la reprise en main de la région demeure très incertaine. Nașr b. Mušarraf continue de harceler les autorités de l'Empire sur les hauteurs. Yahyā relate les déboires de l'axiarque anonyme de Balātunus: alors qu'il conduisait un contingent dans les montagnes, le commandant de la forteresse, capturé par Nașr b. Mušarraf, se résout à offrir une rançon de cinq cents dinars au potentat arabe; Nicétas refusant de payer une telle somme, il faudra attendre l'intervention des troupes byzantines à Bikisrā'̄îl, où il avait été relégué, pour le délivrer manu militari ${ }^{54}$. Ensuite, il est possible que les tribus locales aient repris possession du château assez rapidement au cours du $11^{\mathrm{e}}$ siècle, avant l'établissement de la domination des Turcs seldjoukides ou à la faveur des désordres causés par leur arrivée. On se souvient en effet que le prince franc d'Antioche, en 1118, a dû céder trois villages aux Banū Sulayha pour récupérer Balātunus.

L'un des apports de notre inscription est de montrer que les Byzantins, dans les circonstances délicates que nous venons d'exposer, ont pu s'appuyer sur des Géorgiens pour établir leur autorité sur les tribus de la région. La découverte d'une inscription géorgienne dans les montagnes côtières du Proche-Orient n'est pas une nouveauté en soi. Cependant, aucun texte de ce type n'était connu au sud du Casius jusqu'à présent. Les documents épigraphiques géorgiens sont plus nombreux près d'Antioche, où les Ibères contribuent de manière remarquable au renouveau monastique des $10^{\mathrm{e}}$ et $11^{\mathrm{e}}$ siècles, à la faveur de la sécurité relative assurée par les Byzantins, de la renaissance du patriarcat melkite, de la munificence des souverains géorgiens de la dynastie bagratide et de l'alliance progressivement scellée entre ces derniers et les empereurs de Constantinople ${ }^{55}$. Parmi les personnages emblématiques de ce mouvement se distingue la figure exceptionnelle de Georges l'Hagiorite, moine, traducteur et maître spirituel, né dans le Kartli bagratide

52. Yahyā, Histoire, III, p. 508-515 [140-147]. Selon Jean Skylitzès, Synopsis historiarum, éd. I. Thurn, Berlin et New York 1973, p. 382-383, trad. B. Flusin et J.-C. CheYnet, Paris 2003, p. 317-318, al-Manīqa aurait été livrée par le neveu de Nașr b. Mušarraf aux troupes de l'hétériarque Théoctiste rejointes par Pinzarach, c'est-à-dire Hassān b. al-Mufarriğ al-Ğarrāh, l'émir de Tripoli, tandis que Naṣr b. Mušarraf, abandonnant la citadelle, était capturé et tué aux frontières de Tripoli.

53. YAHYĀ, Histoire, III, p. 514-515 [146-147] et p. 522-529 [154-161], qui n'évoque pas explicitement la mort de Nașr b. Mušarraf, mais qui décrit ses efforts désespérés pour conserver Bikisrā'̄̄l avec l'appui de l'émir fatimide al-Dizbirī.

54. YAHYĀ, Histoire, III, p. 526-527 [158-159].

55. Sur le monde géorgien et ses relations avec Byzance aux $10^{\mathrm{e}}$ et $11^{\mathrm{e}}$ siècles, voir notamment les travaux de synthèse de B. MARTIN-HisARD, Christianisme et Église dans le monde géorgien, dans Histoire du christianisme. IV, Évêques, moines et empereurs (610-1054), éd. J.-M. MAYEUR, Paris 1993, p. 549-603; EADEM, Constantinople et les archontes du monde caucasien dans le Livre des cérémonies, II, 48, TM 13, 2000, p. 359-530; EADEM, L'Anatolie et l'Orient byzantin, dans Le Monde byzantin. II, L'Empire byzantin (641-1204), éd. J.-C. CHeYnet, Paris 2006, p. 397-442. 
vers 1010, formé dans le Samcxe et le Tao jusqu'en 1035 et dans les couvents géorgiens de la Montagne Noire, dans l'Amanus, entre 1036 et 1040, diacre, prêtre, ecclésiarque et higoumène d'Iviron, le monastère des Ibères sur le Mont Athos, en 1040-1056, de nouveau établi dans la région d'Antioche entre 1055 et 1059, puis de retour en Géorgie en 1059-1065, décédé à Constantinople et enfin honoré d'un culte sur l'Athos ${ }^{56}$. La biographie de cet homme, rédigée par Georges, hiéromoine d'Iviron, met en évidence le rôle des Ibères dans les couvents de l'Amanus, du Mont Admirable et du Casius.

Même si leur histoire remonte parfois à la fin de l'Antiquité, plusieurs établissements ecclésiastiques de la région semblent désormais purement géorgiens, tels le monastère Saint-Romain, proche de l'église du Bois de Vie, les couvents de la Mère de Dieu à Calipos (K'alip'o ou K'alip'oli), des Sources (T'vali), de Castana (K'ast'ana), du Père Esdras (Ezra) et de la Vallée des roseaux (Lerc'misxevi), tous situés avec plus ou moins de précision sur les pentes de la Montagne Noire et aux environs d'Antioche, ou encore le monastère Saint-Barlaam, sur le Casius ${ }^{57}$. Certains d'entre eux, au premier chef celui de Calipos, sont d'importants centres de traduction du grec vers le géorgien. À Saint-Syméon le Jeune, sur le Mont Admirable, les Ibères ont leur propre église et possèdent des terres dans les environs. Les inscriptions grecques et géorgiennes des couvents, de même que les colophons des manuscrits qui y sont copiés, font connaître les noms de leurs fidèles et ceux de leurs moines d'origine géorgienne. On ne relève ici apparemment aucun texte épigraphique bilingue.

À Balātunus, plus au sud, l'usage du géorgien comme langue d'affichage dans la dédicace officielle d'un kastron byzantin n'a probablement pas la même signification que dans le milieu monastique où le grec devait être aussi bien compris que le géorgien. Cependant, il implique l'établissement de Géorgiens dans l'arrière-pays de Laodicée et de Gabala, au moins parmi les membres de la ou des garnisons locales qui n'auraient pas lu le grec et à qui la partie géorgienne de notre inscription serait adressée. Vu l'ancienneté et l'importance de la présence géorgienne en Antiochène (qui a notamment valu

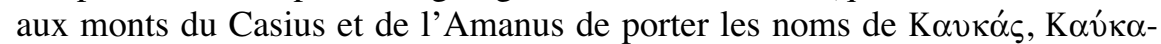

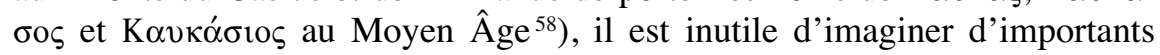

56. B. Martin-Hisard, La Vie de Georges l'Hagiorite (1009/1010-29 juin 1065). Intro duction, traduction du texte géorgien, notes et éclaircissements, $R E B$ 64-65, 2006-2007, p. 5204.

57. J. MÉCÉRIAN, Expédition archéologique dans l'Antiochène occidentale, Beyrouth 1964; J. LAFOnTAINE-Dosogne, Itinéraires archéologiques dans la région d'Antioche. Recherches sur le monastère et sur l'iconographie de S. Syméon Stylite le Jeune, Bruxelles 1967; W. DJoBADZE, Medieval Inscriptions in the Vicinity of Antioch-on-the-Orontes, Oriens Christianus 49, 1965, p. 116-130; IDEM, Materials for the study of Georgian monasteries in the Western environs of Antioch on the Orontes, Louvain 1976; IDEM, Archaeological Investigations in the Region West of Antioch on-the-Orontes, Stuttgart 1986; J.-P. SodinI, Travaux récents sur des bâtiments byzantins et géorgiens à l'Ouest d'Antioche, Journal of Roman Archaeology 1, 1988, p. 229234.

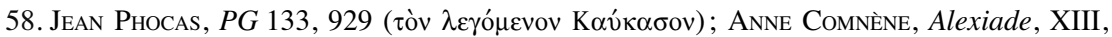
12, 18 (

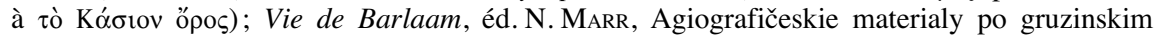
rukopisjam Ivera [Matériaux hagiographiques sur les manuscrits géorgiens d'Iviron], Zapiski 
déplacements de population depuis les pays du Caucase. En revanche, l'idée d'une colonisation militaire ponctuelle par le biais de mercenaires est envisageable, d'après les témoignages qui se rapportent à Spandaghud fils de Tbeli.

Spandaghud fils de Tbeli apparaît dans une série de documents géorgiens qui permettent de retracer le parcours de cet homme depuis le Kartli (l'Ibérie des Byzantins, correspondant à la Géorgie orientale) jusqu'à Laodicée de Syrie et à l'Antiochène. Son nom, tel qu'il est attesté en grec dans notre inscription, transcrit un anthroponyme géorgien qui pourrait être théoriquement

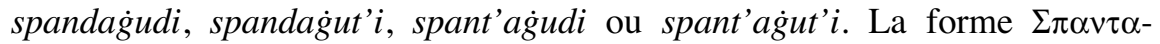
$\gamma o v \delta \eta$, ici précédée de la préposition $\pi \alpha \rho \alpha ́$ et donc normalement déclinée au génitif, implique l'existence du nominatif $* \Sigma \pi \alpha v \tau \alpha \gamma o v \delta \eta \zeta$, à moins qu'elle ne corresponde au calque indécliné du géorgien. Quoi qu'il en soit, le nom du stratège de Laodicée semble extrêmement rare. Nous ne connaissons aucune occurrence de ses variantes théoriques en dehors des textes épigraphiques qui se rapportent manifestement au même personnage et qui garantissent la leçon spandagid, comme on le verra plus loin. En revanche, tbeli, le patronyme de Spandaghud, transcrit en grec T $\eta \pi \varepsilon \lambda$, est fréquemment attesté en Géorgie orientale et méridionale, en particulier parmi les membres d'une illustre famille où il sert à la fois de nom propre personnel et de nom de famille. L'inscription de Balātunus témoigne de cette ambivalence onomastique, sans aucune contradiction. Dans la partie géorgienne du texte, la mention du substantif $d z e-m a n$, «fils» (avec le suffixe ergatif), implique que tbeli est le nom $\mathrm{du}$ père du stratège. La formule onomastique employée en grec fait par

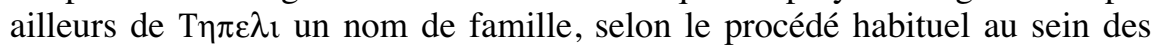
lignées d'étrangers intégrées dans l'Empire byzantin ${ }^{59}$. Dans les deux cas, il s'agit bien du même anthroponyme, dérivé du toponyme tbet'i, nom d'une localité proche de Tsxinvali, au nord-ouest du Kartli intérieur, dans un secteur montagneux que les Tbelis dominent au $10^{\mathrm{e}}$ siècle.

Au début du $10^{\mathrm{e}}$ siècle, l'éristav Jean Tbeli et ses descendants sont les seigneurs les plus puissants sur les hautes terres voisines de Tsxinvali et dans les gorges de la rivière Liaxvi. Ils font construire des églises sur leur domaine à

vostočnago otdèlenija imperatorskago russkago arxeologičeskago obščestva 13, 1901, p. 109138 (en russe); cf. P. Peeters, S. Barlaam du mont Casius, Mélanges de la Faculté Orientale 3 , 2, 1909, p. 805-813, ici p. 807 («Barlaam du Caucase», dans les sources géorgiennes). Voir aussi W. Duobadze, Materials, Louvain 1976, p. 42 et 90, pour le colophon du manuscrit Sinaiticus ibericus 56 (13 $3^{\mathrm{e}}-14^{\mathrm{e}}$ siècles), rappelant la date de la fête de «saint Barlaam sur le mont Caucase» (19 juillet). E. Honigmann, Historische Topographie von Nordsyrien im Altertum, ZDPV 47, 1924, p. 7-8, n²48, allègue également le témoignage d'APOLLODORE,

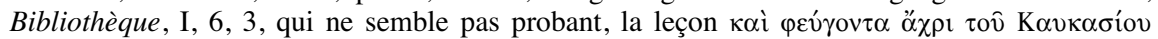

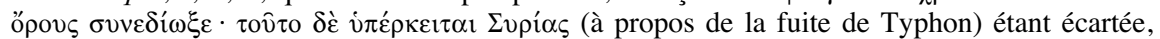

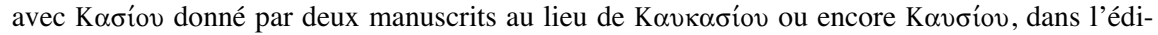
tion de R. Wagner, Mythographi Graeci. I, Apollodori Bibliotheca, Leipzig 1926², p. 17, comme dans la traduction annotée de J.-C.CARrière et B. Massonie, La Bibliothèque d'Apollodore, Paris 1991, p. 34.

59. À ce sujet, voir l'étude classique de J.-C. CHEYnet, Du prénom au patronyme: les étrangers à Byzance $\left(\mathrm{X}^{\mathrm{e}}-\mathrm{XII}^{\mathrm{e}}\right.$ siècles), dans Studies in Byzantine Sigillography 1, éd. N. OiKonOMIDES, Washington 1988, p. 57-66, reprise et complétée dans La société byzantine. L'apport des sceaux, Paris 2008, p. 133-144. 
Tbeti, Eredvi et Dodoti et se distinguent à deux reprises par leur opposition aux Bagratides, eux aussi originaires du Kartli intérieur, mais appelés à régner au cours des $10^{\mathrm{e}}$ et $11^{\mathrm{e}}$ siècles sur les Abkhazes (Géorgie occidentale) et les Kartvéliens (Géorgie orientale) réunis. Ils combattent tout d'abord Georges II (922-957) tout en soutenant son fils Constantin. D'après la Chronique $d u$ Kartli, Georges II, sorti vainqueur des affrontements, se serait contenté de les exiler dans la province arménienne du Vaspurakan ${ }^{60}$. L'emprise des Tbelis sur la région ne cesse pas pour autant. Vers 982, au cours du règne de Bagrat III (978-1014), un groupe de nobles conduits par Kavtar Tbeli s'oppose à nouveau violemment au souverain avant d'être défait près de Moghrisi. Les sources disponibles ne fournissent aucune information sur le sort des Tbelis eux-mêmes. Il paraît toutefois probable que le châtiment que le roi aurait infligé à l'ensemble des insurgés les ait concernés au premier chef. Or, toujours d'après la Chronique du Kartli, «certains moururent, d'autres furent capturés, mais d'autres s'enfuirent, émigrèrent et se dispersèrent ${ }^{61}$.

Bien avant la conclusion de cet épisode, les Tbelis ont reçu des Byzantins le titre de patrice, qui correspond à ce que peuvent espérer obtenir les chefs d'un groupe tribal ou féodal, à l'image de Nașr b. Mušarraf, dans les montagnes côtières de la Syrie. À la fin du $10^{\mathrm{e}}$ siècle, les inscriptions de l'église de Bortsvisjari à Tbeti confèrent notamment cette dignité à un certain Tbeli fils de Kavtar, qui a toutes les chances d'être le père de notre Spandaghud ${ }^{62}$. L'une d'elles mentionne le même homme, désormais défunt, ainsi que les membres de sa famille: Eupraxie (epraqsi), peut-être sa femme, au nom grec, et ses quatre fils. Si les noms de son premier fils (ok'rop'iri) et de ses deux derniers (daviti et k'avt'ari) ne posent pas de problème, il n'en va pas de même de celui du second, dont la forme abrégée n'a pu être déchiffrée depuis la première publication de l'inscription en 1924. Aujourd'hui, il paraît évident que cet anthroponyme doit être lu $s p(a n) d(a) \dot{g}(u) d$ et que son porteur et le Spandaghud de l'inscription de Balātunus ne font qu'un. Une inscription méconnue confirme par ailleurs que Spandaghud fils de Tbeli faisait bien partie de la famille des Tbelis. Le texte est gravé sur les deux faces de l'arche de l'église de Kldeisa, qui s'élève dans la gorge de Xrami, sur le cours de la rivière Kldeisa. Rédigé dans les onciales de l'alphabet asomtavruli, il est daté de la première moitié du $11^{\mathrm{e}}$ siècle selon des critères paléographiques par son éditeur, E. Taq'aišvili, qui n'y a pas reconnu le nom de Spandaghud ${ }^{63}$. En

60. Mat'iane K'art'lisa [Chronique du Kartli], dans K'art'lis c'xovreba [La Vie du Kartli], éd. R. Met'Reveli, Tbilissi 2008, p. 263 (en géorgien); trad. R. W. Thomson, Rewriting Cau casian History. The Medieval Armenian Adaptation of the Georgian Chronicles. The Original Georgian Texts and the Armenian Adaptations, Oxford 1996, p. 255-308, ici p. 269, d'après l'éd. de S. Q'AuxČIŠviLI, I, Tbilissi 1955, p. 249-317, ici p. 267-268.

61. Ibidem, p. 269 ; trad. R. W. Thomson, p. 276 (éd. S. Q’AuxčIšviLi, p. 276-277).

62. N. ŠošIAšVILI, K'art'uli c'arc'erebis k'orp'usi. I, Lap'idaruli c'arc'erebi. 1, Agmosavlet' da samxret' Sak'art'velo ( $V$-X ss.) [Corpus des inscriptions géorgiennes. I, Inscriptions lapidaires. 1, Géorgie orientale et méridionale ( $\left.V^{e}-X^{e} s.\right)$ ], Tbilissi 1980, p. 175-178 (en géorgien).

63. E. TAKaIšVILI [TAQ' AIšVILI], Arxeologičeskie èkskursii, razyskanija i zametki [Excursions archéologiques, recherches et notes], IV, Tbilissi 1913, p. 116-118 (en russe). 
voici la lecture révisée et la traduction: $k^{\prime}($ rist $)$ e, š(eiwyal)e sp(a)nd(a)gid, $k^{\prime}\left(\right.$ rist)e, š(eiwyal)e $k^{\prime}(a) v t^{\prime}(a) r t b(e) l n i$, «Christ, aie pitié de Spandaghud, Christ, aie pitié de Kavtar, les Tbelis ».

L'ensemble des témoignages allégués jusqu'à présent porte à croire que Tbeli fils de Kavtar, le père du futur stratège de Laodicée, faisait partie des hommes tués par les troupes de Bagrat III vers 982, et que ses fils avaient échappé au massacre et à l'exil, peut-être en raison de leur jeune âge. L'inscription de l'église de Kldeisa semble par ailleurs indiquer que Spandaghud se trouvait encore en Géorgie au début du $11^{\mathrm{e}}$ siècle. Les circonstances du départ de ce dernier pour la Syrie peuvent maintenant être précisées. L'historien arménien Aristakès de Lastivert indique que, dans la seconde année de son règne, c'est-à-dire en 1027, l'empereur Constantin VIII envoya l'eunuque Nicétas en Orient avec la charge de gouverneur. Arrivé en Ibérie, Nicétas aurait séduit par des discours astucieux de nombreux nobles géorgiens, qui auraient quitté leurs domaines et qui auraient obtenu des postes importants à la cour de Byzance et se seraient vu attribuer des territoires conséquents ${ }^{64}$. Skylitzès précise l'origine du duc, la Pisidie, laissant ainsi supposer qu'il s'agit de Nicétas de Mistheia, le futur duc d'Antioche, originaire d'une cité de Lycaonie située aux confins de la Pisidie ${ }^{65}$. Quoi qu'il en soit de cette hypothèse, il est probable que Spandaghud fils de Tbeli se trouvait parmi les nobles qui avaient choisi de quitter la Géorgie pour s'engager au service de l'Empire à cette occasion. Son cas ne serait d'ailleurs pas isolé, puisque l'on connaît au Proche-Orient d'autres représentants de l'aristocratie géorgienne promus à des fonctions importantes par les empereurs de Byzance. Selon Matthieu d'Édesse, historien arménien du $12^{\mathrm{e}}$ siècle, lorsque Romain III Argyre attaque Alep en 1030, l'un de ses alliés est le noble Apukap (Apokapès dans les sources grecques), qui était précédemment garde de la tente du roi bagratide David le Curopalate et qui se verra confier dès l'année suivante le duché d'Édesse, après la prise de cette ville ${ }^{66}$.

64. Aristakès de Lastivert [ARIStakēs Lastivertc'í], Récit des malheurs de la nation arménienne, trad. française, introduction et comm. par M. CANARD et H. BERBÉRIAN, d'après l'éd. et la trad. russe de K. YuzBAŠIAn, Bruxelles 1973, p. 27, où le rapprochement entre Nicétas de Pisidie et Nicétas de Mistheia n'est pas proposé. N. Adontz, Notes arméno-byzantines, Byz. 10, 1935, p. 161-203, à qui l'on doit la restitution du nom de Nicétas dans le texte d'Aristakès (p. 180), ne se prononce pas non plus sur l'identité de cet homme.

65. Selon l'hypothèse de R. GuILland, Les eunuques dans l'empire byzantin. Étude de titulature et de prosopographie byzantines, [R]EB 1, 1943, p. 210 (repris dans Recherches sur les institutions byzantines, I, Amsterdam et Berlin 1967, p. 173). Cf. JEAN SKYLITŻ̀s, Synopsis histo-

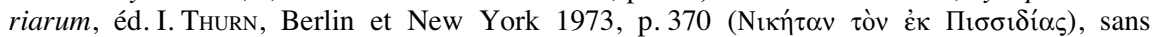
commentaire prosopographique de la part de B. FLUSIN et J.-C. CHEYNET, dans leur traduction annotée de Skylitzès, Paris 2003, p. 305. Sur Mistheia, cf. supra, n. 36.

66. MAtT'Ēos UR่HAYeC'I [MATthieu D’Édesse], Žamanakagrut'iwn [Chronographie], Vałaršapat 1898, p. 57 et 64 (en arménien), trad. A. E. Dostourian, Armenia and the Crusades Tenth to Twelfth Centuries. The Chronicle of Matthew of Edessa, Lanham, Londres et New York 1993, p.51 et 55. Sur l'identification d'Apukap à Basile plutôt qu'à Michel Apokapès, voir J.-C. CheYNeT, Introduction à la sigillographie byzantine, dans La société byzantine. L'apport des sceaux, Paris 2008, p. 76-78, avec un tableau généalogique différent de ceux de P. Lemerle, Le testament d'Eustathios Boïlas (avril 1059), dans Cinq études sur le XI siècle 
$\mathrm{Au}$ Proche-Orient, on retrouve encore la trace du stratège de Laodicée neuf ans après la prise et la restauration de Balātunus, dans le colophon d'un manuscrit géorgien traduit du grec et copié en 1040 «dans le pays de la Syrie, à la frontière d'Antioche, près de Syméon Thaumaturge, dans la laure de la sainte Mère de Dieu, le monastère géorgien de Calipos ». Le texte introduit la biographie et des discours de Grégoire le Théologien (Grégoire de Nazianze, vers 330-390). Destiné à être offert au monastère géorgien de la Sainte-Croix à Jérusalem, il porte notamment la brève invocation suivante: «Christ, maître de toutes choses, glorifie dans ses deux vies le patrice Spandaghut, amen $\gg{ }^{67}$. Le nom du stratège de Laodicée est orthographié d'une manière légèrement différente (spandagut) de celle que l'on trouve dans les autres documents géorgiens. Pour autant, il désigne sans doute le même homme. Le fait que Spandaghud soit désigné uniquement par son titre de patrice renforce l'identification proposée, sans impliquer toutefois que le stratège ait été démis de ses fonctions en 1040.

Le parcours de Spandaghud fils de Tbeli, de la Géorgie orientale aux montagnes côtières de la Syrie et à l'Antiochène, s'inscrit dans un mouvement migratoire séculaire, dont l'ampleur est difficile à évaluer, mais dont les causes et les manifestations méritent d'être brièvement rappelées. La fidélité des Géorgiens à l'orthodoxie chalcédonienne, qui les oppose à la majorité monophysite des Arméniens et aux Syriens jacobites, est en soi un facteur susceptible de favoriser des rapprochements avec Byzance ${ }^{68}$. Les empereurs de l'époque de la Reconquête byzantine n'ont pas à craindre qu'ils forment une hiérarchie ecclésiastique dissidente au sein des territoires qu'ils enlèvent aux musulmans. Ils bénéficient aussi à plusieurs reprises du soutien de Géorgiens lors d'opérations militaires dirigées contre leurs ennemis de l'extérieur et de l'intérieur. En 964, Nicéphore Phocas conduit déjà en Cilicie «une puissante armée faite de Romains et d'alliés ibères et arméniens ${ }^{69}$. Lors des deux grandes rébellions de 976-979 et de 987-989, les Phocas peuvent à nouveau compter sur eux, en particulier sur Tornik (T'ornik, dit Jean le Syncelle, mort en 984), le célèbre chef militaire et moine fondateur d'Iviron, et sur sa famille, les Črdvaneli, y compris lors de leur opposition à Basile II (976-

byzantin, Paris 1977, p. 15-63, ici p. 49-53, et de M. GrünBART, Die Familie Apokapes im Lichte neuer Quellen, dans Studies in Byzantine Sigillography 5, éd. N. OiKonOMIDES, Washington 1998, p. 29-41. Les descendants d'Apukap ont été ducs d'Édesse à leur tour au cours du $11^{\mathrm{e}}$ siècle. Voir aussi J.-C. CHeYnet, Sceaux de la collection Zacos, Paris 2001, p. 6061, n 30 (Untel Apokapès, patrice, vestès et catépan d'Édesse, au milieu du 11 e siècle), p. 63, $\mathrm{n}^{\circ} 32$; cf. IDEM, Sceaux de la collection Khoury, Revue numismatique 159, 2003, p. 425-427, $\mathrm{n}^{\text {os }}$ 7-8 (Basile Apokapès, dans les années 1070).

67. T. Zhordania, Qronikebi [Chroniques], Tbilissi 1892, p. 180; W. DJobadZe, Materials, Louvain 1976, p. 5-12, manuscrit P 3, citations aux p. 9 et 10.

68. Selon YAHYĀ, Histoire, III, p. 489 [121], Romain III Argyre estime, en 1031, que les Abkhazes «sont des chrétiens, orthodoxes quant à la foi et aux pratiques, avec lesquels vivre en bonne intelligence et mettre fin à la méfiance réciproque s'imposent».

69. Jean Skylitzès, Synopsis historiarum, éd. I. Thurn, Berlin et New York 1973, p. 268, avec le commentaire de B. Flusin et J.-C. Cheynet, dans JeAn Skylitzès, Empereurs de Constantinople, Paris 2003, p. 225 n. 33, d'après YẠYĀ, Histoire, I, p. 793 [95] (qui date la campagne plus précocement). 
1025), tandis que les Arméniens soutiennent traditionnellement Bardas Sklèros, notamment à Antioche ${ }^{70}$.

Au début du $11^{\mathrm{e}}$ siècle, les liens entre l'Empire et la Géorgie sont encore renforcés par la formation du duché dit d'Ibérie à partir de l'héritage de David le Curopalate dans le Tao, soit immédiatement après la mort de ce souverain, en 1001, soit seulement entre 1025 et 1027, après la victoire de Basile II sur Georges Ir , roi des Abkhazes et des Ibères (1014-1027) ${ }^{71}$. En 1031, Romain III Argyre et les Ibères représentés par la reine Marie, agissant au nom de son fils mineur Bagrat IV, et par le catholicos Melchisédech, concluent un traité de paix qui entérine la situation. Bagrat IV (1027-1072) reçoit alors à son tour la dignité de curopalate et épouse Hélène, la nièce de l'empereur. L'aristocratie géorgienne, divisée, voit une partie de ses membres se mettre au service de Byzance.

Avant comme après la création du duché d'Ibérie, des fonctionnaires militaires et des dignitaires byzantins d'origine géorgienne (ou dans certains cas probablement des Caucasiens chalcédoniens géorgianisés) sont présents en Syrie du Nord. Nous ne citerons ici que quelques noms, sans souci d'exhaustivité. Un certain Pankratios (Bagrat) Diogène, peut-être issu de l'union d'un Diogène et d'une descendante des Bagratides géorgiens, est protospathaire et catépan d'Antioche, probablement sous Basile II $^{72}$. Le patrice Čordvaneli, fils de Jean Varasvače et neveu de Tornik, fait partie des prisonniers capturés par les troupes fatimides lors de la bataille d'Apamée, où le duc d'Antioche Damien Dalassènos trouve la mort, le 19 juillet $998^{73}$. Isaac Ibèros est peutêtre stratège de Laodicée entre 975 et $1000^{74}$. Apasios, magistre et frère du sébaste et grand domestique d'Occident Grégoire Pakourianos (Grigol

70. J.-C. Cheynet, Pouvoir et contestations à Byzance (963-1210), Paris 1990, p. 28, 31, 33 et 329-336. Sur Tornik et sa famille, voir J. LEFORT, Histoire du monastère d'Iviron, des origines jusqu'au milieu du $\mathrm{XI}^{\mathrm{e}}$ siècle, dans J. LeForT, Histoire du monastère d'Iviron, dans Actes d'Iviron, I, éd. J. Lefort et al., Paris 1985, p. 15-17; E. Met'Reveli, Čordvanelta didi saxlis istoriisatvis, Čordvanelta didi saxli da Ivironi [Sur l'histoire de la grande maison des Čordvaneli, La grande maison des Čordvaneli et l'Iviron], dans EADEM, Narkvevebi Atonis k'ult'urul-saganmanatlebul k'eris ist'oriidan [Matériaux pour l'histoire du foyer culturel d'Iviron], Tbilissi 1996, p. 5-57 et 263-315 (en géorgien); B. Martin-HisARD, La Vie de Georges l'Hagiorite, REB 6465, 2006-2007, p. 20, 130, 136.

71. Sur ces événements, voir B. Martin-Hisard, L'Anatolie et l'Orient byzantin, dans Le Monde byzantin. II, L'Empire byzantin (641-1204), éd. J.-C. CHEYnet, Paris 2006, p. 423-424.

72. J.-C. Cheynet, Grandeur et décadence des Diogénai, dans The Empire in Crisis (?), éd. V. N. Vlyssidou, Athènes 2003, p. 119-138, repris dans La société byzantine. L'apport des sceaux, Paris 2008, p. 563-581, ici p. 573. J.-C. Cheynet nous indique toutefois que ses recherches récentes sur les Tarônitai l'amènent à penser que le catépan d'Antioche Pankratios pourrait être lié à cette famille d'origine arménienne.

73. SteP'anos Tarawnec'i AsoŁIK [Étienne AsoŁIK de Tarōn], Patmut'iwn tiezerakan [Histoire universelle], III, 37, trad. F. MACLER, Paris 1917, p. 151; cf. J. Lefort, Histoire du monastère d'Iviron, dans Actes d'Iviron, I, éd. J. LeForT et al., Paris 1985, p. 16 n. 4 (où la capture de Čordvaneli est datée en 988-989 par inadvertance). Les auteurs arabes qui relatent la bataille d'Apamée (Yahyāan, Ibn al-Ațīr, Ibn al-Qalānisī) n'évoquent pas ce Čordvaneli. Voir M. CANARD, Les sources arabes de l'histoire byzantine aux confins des $\mathrm{X}^{\mathrm{e}}$ et $\mathrm{XI}^{\mathrm{e}}$ siècles, $R E B$ 19, 1961, p. 284-314, ici p. 297-300 (avec la traduction d'Ibn al-Qalānisī), et Th. BIANQUis, Damas et la Syrie sous les Fatimides, Damas 1986-1989, p. 239-242.

74. J.-C. Cheynet, Sceaux de la collection Zacos, Paris 2001, p. 76. 
Bakurianisdze), obtient une commune rurale du thème de Thessalonique en échange de biens qu'il possédait jusqu'alors à Antioche, probablement à la fin du règne de Michel VII Doukas (1067-1078) ${ }^{75}$. En 1068, à la suite de la victoire de l'empereur Romain IV Diogène sur les Turcs près d'Antioche, le vestès Pharasmanès (Parsman) Apokapès, fils de Michel Apokapès, qualifié tantôt de Géorgien, tantôt d'Arménien, est nommé stratège de la citadelle de Hiérapolis de Syrie ${ }^{76}$. Enfin, un Tornikios Barasbatzé (Varasvače), porteur du titre aulique de protovestès et peut-être apparenté aux Čordvaneli, est encore signalé dans la région d'Antioche dans le dernier quart du $11^{\mathrm{e}}$ siècle $^{77}$. Il faut désormais ajouter à cette liste Spandaghud fils de Tbeli, ainsi que tout ou partie des soldats byzantins de Balātunus.

\author{
Julien AliQuot \\ UMR 5189 Hisoma, CNRS, Lyon
}

\title{
Zaza AleKsidZÉ \\ Académie des Sciences de Géorgie, Tbilissi
}

75. A. Š ANIDZE, K'art'velt'a monasteri bulgaret'ši da misi tipikoni. Tipikonis k'artuli redak'c'ia [Le monastère géorgien en Bulgarie et ses typika. La version géorgienne du typikon], Tbilissi 1971, p. 9-368, en particulier p. 13-57 (en géorgien); P. GAUTIER, Le typikon du sébaste Grégoire Pakourianos, REB 42, 1984, p. 5-145, en particulier p. 38-39; R. JoRDAN, Typikon of Gregory Pakourianos for the Monastery of the Mother of God Petritzonitissa in Bačkovo, dans Byzantine Monastic Foundation Documents, éd. J. Thomas et A. C. Hero, II, Washington 2000, p. 507-563, ici p. 525 et 558 n. 8 .

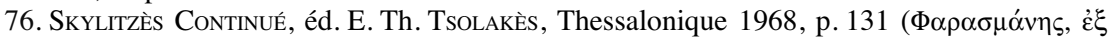

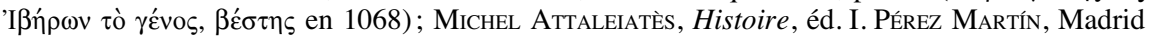

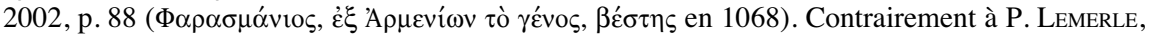
Le testament d'Eustathios Boïlas (avril 1059), dans Cinq études sur le XI siècle byzantin, Paris 1977, p. 29 et p. 51-53, M. GrÜNBART, Die Familie Apokapes im Lichte neuer Quellen, dans Studies in Byzantine Sigillography 5, éd. N. OIKONOMIDEs, Washington 1998, p. 31 et 40-41, distingue cet homme, peut-être de manière excessive, du fils homonyme de Michel Apokapès, qui serait bien de la même génération, mais dont le titre de vestarque serait supérieur à celui de ves-

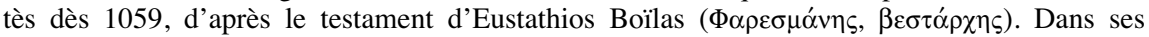
observations sur le stemma des Apokapai, J.-C. CHEYNET, Introduction à la sigillographie byzantine, dans La société byzantine. L'apport des sceaux, Paris 2008, p. 78, ne se prononce pas sur ce point; p. 138, il publie le sceau d'un Apokapès Pharesmanès, protospathaire et stratège, qui serait notre homme, au début de sa carrière. Aux témoignages connus sur Pharasmanès, on ajoutera encore le sceau en plomb inédit de Pharasmanès Apokapès référencé sur le site www .acsearch.info, $\mathrm{n}^{\circ} 10459$ (17,66 g). On y lit, au droit, $\mathrm{M}\left(\dot{\eta}^{\prime} \tau \eta\right) \rho \Theta(\varepsilon 0) \hat{v}$, dans le champ de part et d'autre de la Vierge des Blachernes (en buste, orante, portant le médaillon de l'Enfant sur

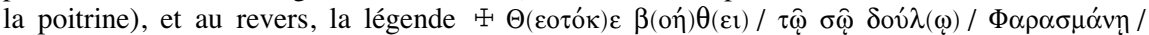

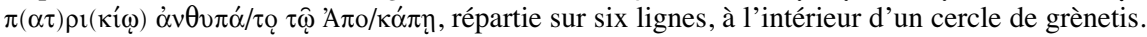
Ce monument, s'il concerne bien le même personnage, est antérieur aux époques évoquées dans les textes cités ci-dessus en raison de l'infériorité des titres d'anthypatos et de patrice par rapport à ceux de vestarque et de vestès.

77. J.-C. Cheynet, C. Morrisson et W. SeIbt, Les sceaux byzantins de la collection Henri Seyrig, Paris 1991, p. 57, nº 63 ; J.-C. CHEYNET, Sceaux de la collection Khoury, Revue numismatique 159, 2003, p. 446-447, n 34. Cet homme doit être distingué d'un protospathaire et stratège homonyme qui est connu par un sceau et qui serait lui-même identifiable au protospathaire Barasbatzé l'Ibère, catépan d'Édesse en 1037-1038, et à l'un des fils de Jean Varasvače (cf. J. Lefort, Histoire du monastère d'Iviron, dans Actes d'Iviron, I, éd. J. Lefort et al., Paris 1985 , p. 16 n. 5). 


\title{
APPENDICE \\ Les inscriptions grecques des territoires de la Reconquête byzantine au Proche-Orient
}

\author{
Julien AliQuot
}

Cet inventaire regroupe les textes épigraphiques rédigés en grec à l'intérieur des territoires que les Byzantins ont dominés en Syrie du Nord et en Mésopotamie au cours des $10^{\mathrm{e}}$ et $11^{\mathrm{e}}$ siècles et qu'ils ont continué à détenir, bien que de manière partielle et théorique, dans le cadre de la principauté franque d'Antioche, aux $12^{\mathrm{e}}$ et $13^{\mathrm{e}}$ siècles. De nouvelles découvertes et un examen aussi systématique que possible de l'ensemble des inscriptions médiévales du Proche-Orient pourraient peut-être l'enrichir. Seules les références aux éditions et aux travaux qui permettent d'établir les textes sont citées, avec les renvois au corpus des Inscriptions grecques et latines de la Syrie (IGLS), au Bulletin épigraphique de la REG (ci-après Bull. ép., suivi du numéro de la notice) et au recueil récent de D. FeIssel, Chroniques d'épigraphie byzantine 1987-2004, Paris 2006 (D. FeIssel, Chroniques). Sont exclus, outre quelques cas douteux ${ }^{78}$, les inscriptions médiévales des régions qui n'ont jamais été réintégrées dans l'Empire à la suite de la Reconquête byzantine du Proche-Orient, d'une part, et celles des autres périodes, d'autre part ${ }^{79}$.

78. J. JARRY, Trouvailles épigraphiques à Saint-Syméon, Syria 43, 1966, p. 108-110, nos 3-4 (fragments de Qal'at Sam'ān); IDEM, Inscriptions arabes, syriaques et grecques du massif du Bélus en Syrie du Nord, Annales islamologiques 7, 1967, p. 185, n 108 (graffito de Déhès), et p. 187, no 115; cf. IDEM, Nouveaux documents grecs et latins de Syrie du Nord et de la Palmyrène, Zeitschrift für Papyrologie und Epigraphik 60, 1985, p. 109, nº 1, révisant IGLS. II, 586 (dédicace du kastron de Me'ez).

79. P.-L. Gatier, Les inscriptions grecques d'époque islamique (VII $-\mathrm{VIII}^{\mathrm{e}} \mathrm{s}$.) en Syrie du Sud, dans La Syrie de Byzance à l'Islam, VII ${ }^{e}$-VIII e siècles, éd. P. CANIVET et J.-P. ReY-CoQuAIs, Damas 1992, p. 145-157, et IDEM, Inscriptions grecques, mosaïques et églises des débuts de l'époque islamique au Proche-Orient ( $\mathrm{VII}^{\mathrm{e}}$-VIIII ${ }^{\mathrm{e}} \mathrm{s}$.), dans Le Proche-Orient de Justinien aux Abbassides. Peuplement et dynamiques spatiales, éd. A. Borrut, M. Debié, A. Papaconstantinou, D. Pieri et J.-P. SodinI, Turnhout 2012, p. 7-28, dresse un inventaire et propose une synthèse historique pour l'épigraphie grecque des époques omeyyade et abbasside. Il n'existe pas d'étude semblable pour les périodes plus récentes. On se contentera de signaler quelques publications intéressantes, en suivant un ordre géographique, du nord au sud. - L. JALABERT et R. Mouterde, IGLS. I, Commagène et Cyrrhestique, Paris 1929, p. 61, no 58 : bilingue grecque et syriaque mentionnant le patriarche jacobite d'Antioche Denys I $^{\text {er }}$ (818-845), l'évêque Théodore de Kaisoum et Maris, le supérieur du monastère Saint-Jacques. - J.-P. REY-CoQUAIS, Inscriptions grecques et latines de Tyr, Beyrouth 2006, p. 136, n² 299, cf. D. Feissel et P.-L. GATIER, Bull. ép. 2007, 515 : épitaphe lacunaire peut-être datée selon l'ère mondiale byzantine, plutôt d'époque croisée, Tyr n'ayant jamais appartenu aux territoires de la Reconquête. - G. KüHnel, The Twelfth-Century Decoration of the Church of the Nativity: Eastern and Western Concord, dans Ancient Churches Revealed, éd. Y. Tsafrir, Jérusalem 1993, p. 197-203, pl. 12-14 (D. Feissel, Bull. ép. 1995, 634; Idem, Chroniques, p. 217, no 696): mosaïques de la Nativité de Bethléem, $12^{\mathrm{e}}$ siècle. J. Patrich, Sabas, Leader of Palestinian Monasticism, Washington 1995, p. $63-66$ (D. Feissel, Bull.ép. 1998, 523; Idem, Chroniques, p. 236-237, $\mathrm{n}^{\circ}$ 757): faux épigraphique de la tour dite de Justinien au monastère Saint-Sabas, près de Jérusalem, d'époque croisée ou postérieure. - 
De manière attendue, la majorité des inscriptions proviennent d'Antioche et de ses environs. Elles consistent pour la plupart en des épitaphes de moines, de clercs et de dignitaires de l'Empire byzantin. Le caractère bilingue, grec et arabe, de l'une d'entre elles évoque l'arabisation des chrétiens melkites de la Syrie du Nord. Les deux textes commémorant la construction ou la reconstruction des citadelles à Antioche et à Qal'at Sam'ān doivent être rapprochés de celui de Balāțunus.

\section{ANTIOCHE}

1. Épitaphe du moine Jacob, datée du 23 avril 1042, au dos d'une stèle portant quelques lettres d'une inscription arabe coufique monumentale antérieure, sans doute de la première moitié du $10^{\mathrm{e}}$ siècle.

G. Downey, Greek and Latin inscriptions, dans Antioch on-the-Orontes. II, The Excavations 1933-1936, éd. R. STILLwell, Princeton 1938, p. 158-160, nº 85, ph. (lecture corrigée par H. GRÉGOIRE, Notules épigraphiques III : sur une inscription d'Antioche, ou de l'utilité du grec moderne et de la liturgie pour l'épigraphie byzantine, Byz.13, 1938, p. 177-179, et par R. Mouterde, Bibliographie, Mélanges de l'Université Saint-Joseph 22, 1939, p. 131; L. Jalabert et R. Mouterde, IGLS. III, 1, Région de l'Amanus. Antioche, Paris 1950, p. $463, \mathrm{n}^{\circ} 814$; J. et L. ROBERT, Bull. ép. 1958, 500).

2. Épitaphe du moine Eustratios, non datée, mais d'une paléographie comparable à celle de la précédente.

G. Downey, op. cit., p. 160, $\mathrm{n}^{\circ}$ 86, ph. (L. JALABERT et R. MOUTERDE, IGLS. III, 1, Région de l'Amanus. Antioche, Paris 1950, p. 463-464, n 815 ).

3. Épitaphe de Bardas, $1^{\text {er }}$ décembre 1063.

G. DownEy, Greek and Latin inscriptions, dans Antioch on-the-Orontes. III, The Excavations 1937-1939, éd. R. Stillwell, Princeton 1941, p. 92, nº 145, ph. (L. Jalabert et R. Mouterde, IGLS. III, 1, Région de l'Amanus. Antioche, Paris 1950, p. 461-462, no 810).

4. Épitaphe lacunaire, non datée.

G. DOWNey, op. cit., p. 94-96, no 158 , ph. (L. JALABERT et R. MOUTERde, IGLS. III, 1, Région de l'Amanus. Antioche, Paris 1950, p. 481-482, no 869); Ch. Kondoleon, Byzantine Inscription (Epitaph), dans Antioch, the lost ancient city, éd. Ch. Kondoleon et al., Princeton 2000, p. 143, n ${ }^{\circ}$ 37, ph. (D. Feissel, Bull. ép. 2001, 587; IDEM, Chroniques, p. $\left.187, \mathrm{n}^{\circ} 587\right)$.

5. Fragment d'épitaphe métrique, $10^{\mathrm{e}}-11^{\mathrm{e}}$ siècle.

L. Jalabert et R. Mouterde, IGLS. III, 1, Région de l'Amanus. Antioche, Paris 1950, p. 526, no 986, d'après la ph. de R. Mouterde, Antiquités et inscriptions (Syrie, Liban), Mélanges de l'Université Saint-Joseph 26, 1944-1946, pl. 1, 3 (inscription aimablement signalée à notre attention par $\mathrm{D}$. Feissel).

I. ŠEvČEnko, The Lost Panels of the North Door to the Chapel of the Burning Bush at Sinai,

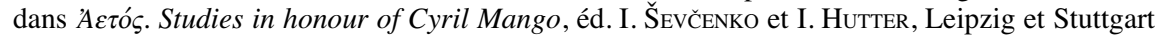
1998, p. 284-298 (D. Feissel, Bull. ép. 1999, 574, et Idem, Chroniques, p. 257, no 820): épigrammes de la chapelle du Buisson Ardent sur le Sinaï, peut-être du début du $10^{\mathrm{e}}$ siècle. 
6. Épitaphe bilingue, grecque et arabe, d'un Basile, 999.

G. Dagron, dans G. Dagron et D. Feissel, Inscriptions inédites du Musée d'Antioche, TM 9, 1985, p. 457-459, nº 3, ph. (D. FeIsSel, Bull.ép. 1987, 497; Idem, Chroniques, p. 187, $\left.\mathrm{n}^{\circ} 586\right)$.

7. Inscription commémorant probablement la construction ou la reconstruction des remparts, peut-être à la fin du $10^{\mathrm{e}}$ siècle.

G. Dagron, op. cit., p. 459-460, no 4, ph. (D. Feissel, Bull. ép. 1987, 497; IDEm, Chroniques, p. $187, \mathrm{n}^{\circ}$ 586).

8. Fragment d'épitaphe d'un Théodôros, $10^{\mathrm{e}}-11^{\mathrm{e}}$ siècle.

G. Dagron, op. cit., p. 460, n 5, ph. (D. Feissel, Bull. ép. 1987, 497; Idem, Chroniques, p. $\left.187, \mathrm{n}^{\circ} 586\right)$.

9. Épitaphe d'un clerc de la Grande Église, du 2 janvier 1046.

G. Dagron, op. cit., p. 460-461, no 6, ph. (D. Feissel, Bull. ép. 1987, 497; Idem, Chroniques, p. 187, $\mathrm{n}^{\circ}$ 586).

10. Dédicace lacunaire d'un bâtiment sur la route d'Antioche à Daphné, $10^{\text {e }}$ $11^{\mathrm{e}}$ siècle.

L. Jalabert et R. Mouterde, IGLS. III, 2, Antioche (suite). Antiochène, Paris 1953, p. 531$533, \mathrm{n}^{\circ} 990$.

Notre collègue D. Feissel, qui a pu revoir l'inscription au musée d'Antioche en 1993 et qui en prépare une réédition, nous fait savoir que cette dédicace ne remonte pas au $6^{\mathrm{e}}$ siècle $(I G L S)$, mais doit dater du $10^{\mathrm{e}}$ ou du $11^{\mathrm{e}}$ siècle, à la fois d'après sa paléographie et d'après la

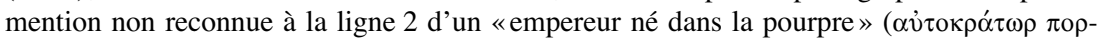

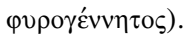

\section{Antiochène: Saint-Syméon Stylite l’Ancien (QAL“at Sam‘ān)}

11. Dédicace de la forteresse médiévale, sous Christophoros, patriarche melkite de Théoupolis-Antioche (960-969), vers 966.

J. JARRY, Trouvailles épigraphiques à Saint-Syméon, Syria 43, 1966, p. 107-108, no 2 (J. et L. Robert, Bull.ép. 1967, 633); J.-P. SodinI, Qal'at Sem'an: quelques données nouvelles, dans Akten des XII. internationalen Kongresses für christliche Archäologie, Bonn, 22.-28. September 1991, éd. E. Dassmann et J. Engemann, I, Münster et Vatican 1995, p. 348-368, ici p. 363-364, ph., avec un nouveau fragment, lecture de D. Feissel (D. FeIssel, Bull. ép. 1997, 637; IDEM, La citadelle médiévale de Qal'at Sam'an, dans Choix d'inscriptions grecques et latines de la Syrie, éd. J.-B. Yon et P.-L. Gatier, Beyrouth 2009, p.92-93, $\mathrm{n}^{\circ} 20, \mathrm{ph}$.).

Cf. J. Nasrallah, À propos des trouvailles épigraphiques à Saint-Siméon-l'Alépin, Syria 48, 1971, p. 165-178, ici p. 167-170 (J. et L. Robert, Bull. ép. 1972, 567), qui doute du caractère byzantin de la dédicace, en se fondant sur la biographie du patriarche Christophoros, éditée et traduite de l'arabe par H.ZAYAT, Vie du patriarche melkite d'Antioche Christophore $(† 967)$ par le protospathaire Ibrahîm b. Yuhanna. Document inédit du $\mathrm{x}^{\mathrm{e}}$ siècle, Proche-Orient chrétien 2, 1952, p. 11-38 et 333-366, en particulier $\S 11$, p. 336-339; W. SAUNDERS, Qal'at Seman: a frontier fort of the tenth and eleventh centuries, dans Armies and Frontiers in Roman and Byzantine Anatolia, éd. S. Mitchell, Oxford 1983, p. 291-303 (trad., comm.); J.-L. BIscop, The "Kastron" of Qal'at Sim'ān, dans Muslim Architecture in Greater Syria, from the Coming of Islam to the Ottoman Period, éd. H. KeNNEDY, Leyde 2006, p.75-83 (comm., architecture et archéologie du kastron); J.-P. SodinI, Saint Syméon, lieu de pèlerinage, Les Cahiers de Saint-Michel de Cuxa 38, 2007, p. 107-120, en particulier p. 118 (kastron). 
12. Inscription bilingue, grecque et syriaque, de la mosaïque de la nef de la basilique est, commémorant la reconstruction et la fortification du monastère sous les empereurs Basile II et Constantin VIII, en 979.

H. Lietzmann, dans D. KrencKer, Die Wallfahrtskirche des Simeon Stylites in Kal'at Sim'ân, Berlin 1939, p. 27, fac-similé et ph., pl. 23 (B. MeISSNER, Ein griechisch-syrische Bilingue aus Qal'at Sim‘ân, Zeitschrift der deutschen Morgenländischen Gesellschaft 94, 1940, p. 372-374 ; E. LitTMAnN, Zu den Inschriften von Qal'at Sim'ân, Zeitschrift der deutschen Morgenländischen Gesellschaft 95, 1941, p. 311-316, avec une inscription syriaque de la même année; R. Mouterde, dans J. Mattern, Villes mortes de Haute Syrie, Beyrouth $1944^{2}$, p. 131 n. 1, texte grec seul ; J. OBermanN, A Composite Inscription from the Church of St. Simeon the Stylite, Journal of Near Eastern Studies 5, 1946, p. 73-82, dont les propositions sont insoutenables); P. DonceEL-Voûte, Les pavements des églises byzantines de Syrie et du Liban, Louvain 1988, p. 234-237, ph.

Cf. G. Tchalenko, Villages antiques de la Syrie du Nord, I, Paris 1953, p. 240-241 (comm.); J.-P. Sodin, Saint Syméon, lieu de pèlerinage, Les Cahiers de Saint-Michel de Сuxa 38, 2007, p. 119-120, fig. 23 (ph., trad., comm.).

\section{Amanus}

13. Épitaphe à l'église Saint-Mélèce de Bityas, datée approximativement du $9^{\mathrm{e}}$ ou du $10^{\mathrm{e}}$ siècle.

L. Jalabert et R. Mouterde, IGLS. III, 2, Antioche (suite). Antiochène, Paris 1953, p. 602, $\mathrm{n}^{\circ} 1107$.

14. Épitaphe versifiée à l'église de la Vierge de Bityas.

L. JaLABERT et R. Mouterde, IGLS. III, 2, Paris 1953, p. 602-603, nº 1108, avec fac-similé.

15. Graffitis grecs de l'église médiévale géorgienne du Bois de Vie, datés approximativement du $12^{\mathrm{e}}$ ou du $13^{\mathrm{e}}$ siècle.

H. Seyrig, dans W. DJobadze, Archaeological Investigations in the Region West of Antioch on-the-Orontes, Stuttgart 1986, p. 205, $\mathrm{n}^{\mathrm{os}} \mathrm{V}, 17-18$.

\section{Séleucie: Saint-Syméon Stylite le Jeune}

16. Dédicace versifiée d'une mosaïque de l'église de la sainte Trinité, au monastère de Saint-Syméon Stylite le Jeune, probablement du $11^{\mathrm{e}}$ siècle.

C. Mango, dans W. Duobadze, Archaeological Investigations in the Region West of Antioch on-the-Orontes, Stuttgart 1986, p. 204, no V, 14, ph. (D. FeIssel, Bull. ép. 1991, 741; IDEM, Chroniques, p. 193, n ${ }^{\circ}$ 611; J.-P. ReY-CoQuals, Inscriptions du Mont Admirable, Mélanges de l'Université Saint-Joseph 52, 1991-1992, p. 223; D. FeIsSEL, Bull. ép. 1996, 470; IDEM, Chroniques, p. 194, $\mathrm{n}^{\circ}$ 613, in fine).

17. Inscription sur mosaïque au nom de l'archimandrite dans la même église et sans doute contemporaine du texte précédent.

W. Duobadze, op. cit., p. 75 et 205, $\mathrm{n}^{\circ} \mathrm{V}, 15$, ph.; P. Donceel-Voûte, Les pavements des églises byzantines de Syrie et du Liban, Louvain 1988, p. 189, fac-similé, fig. 163.

18. Épitaphe versifiée en dodécasyllabes du moine Sisinnios, au chevet de l'église sud, non datée («de préférence à partir du vIII ${ }^{\mathrm{e}} \mathrm{s}$.» selon D. Feissel).

J. Mécérian, Les inscriptions du Mont Admirable, Mélanges de l'Université SaintJoseph 38, 1962, p. 324-326, no VI, ph., pl. 9, 1, révisée par J.-P. ReY-CoQuAIs, Inscriptions du Mont Admirable, Mélanges de l'Université Saint-Joseph 52, 1991-1992, p. 214-216, $\mathrm{n}^{\circ}$ III, et par D. Feissel, Bull. ép. 1996, 470 (Idem, Chroniques, p. 194, nº 613). 
19. Épitaphe de Nicéphore, dans le narthex nord, 29 avril 1266.

J. MécÉrian, op. cit., p. 322, nº V, 1, ph., pl. 7, 1 (J. Darrouzès, Bulletin critique, REB 22, 1964, p. 286) ; J.-P. ReY-CoQuais, op. cit., p. 220-221, no VI, 1 (D. FeIssel, Bull. ép. 1996, 470 ; IDEM, Chroniques, p. 194, nº 613).

20. Épitaphe du moine Macarios fils de Sayf, dans le narthex nord, 3 janvier 1193. Au

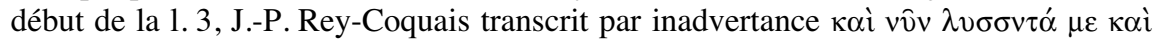

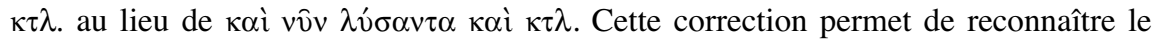
caractère métrique du texte, passé inaperçu jusqu'à présent: l'épitaphe, gravée sur quatre lignes, se compose de six dodécasyllabes, puis d'une formule en prose rappelant le nom du moine, son patronyme et la date de son décès.

J. MécÉRIAn, op. cit., p. 322-323, no V, 2, copie en majuscules, trad., ph., pl. 8, 3 ; J.-P. ReYCoquais, op. cit., p. 220-221, n VI, 2 (D. FeIssel, Bull. ép. 1996, 470; IDEM, Chroniques, p. 194, $\mathrm{n}^{\circ}$ 613).

21. Épigramme lacunaire, avec invocation à la Vierge pour le donateur qui a fait couvrir le narthex nord de sa chapelle, non datée.

J. Méć́rian, op. cit., p. 323, n V, 3, ph., pl. 8,1 (J. Darrouzès, Bulletin critique, REB 22, 1964, p. 286); J.-P. ReY-CoQuaIs, op. cit., p. 221-222, nº VI, 3.

22. Épitaphe lacunaire d'un natif d'Édesse, fils de Daniel, dans le narthex nord, non datée.

J. Mécérian, op . cit., p. 324, no V, 4, ph., pl. 8, 2 (J. DarrouZÈs, Bulletin critique, REB 22, 1964, p. 286); J.-P. REY-CoQUAIS, op. cit., p. 222, nº VI, 4.

23. Invocations peintes des deux moines Théodore et Pierre et épitaphe du même Pierre, permettant d'identifier les donateurs et les orants prosternés aux pieds du Christ sur la fresque qui orne le mur situé à gauche de la porte monumentale du couvent, à l'intérieur du complexe monastique, non datées.

J.-P. Rey-CoQuais, op. cit., p. 217-219, nº V, 1-3.

\section{GABALA}

24. Épitaphe de Jean, protopapas de la Grande Église de Gabala et avoué, 25 mars 1043. La révision du texte au musée de Tartous révèle que, au-dessus du texte, une ligne a été omise dans les précédentes éditions : [- - ] vac. ఆỴ. On peut restituer l'invocation banale à la Mère de Dieu, $\left[\mathrm{M}\left(\eta_{\eta}^{\prime} \tau \eta\right) \rho\right] \Theta(\varepsilon 0) \hat{v}$.

C. MANGo, Deux inscriptions byzantines de Gabala en Syrie, TM 9, 1985, p. 463-464, nº 1, ph. (D. Feissel, Bull.ép. 1987, 505 ; Idem, Chroniques, p. 194, nº 614).

25. Épitaphe du moine Nicodème, 22 août, indiction 12, d'une année incertaine. Revu

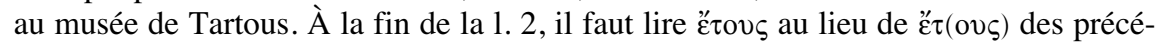
dents éditeurs. Ensuite, C. Mango lit , $\varsigma \varphi v \alpha^{\prime}$ au-dessus de,$\varsigma \varphi \xi \eta^{\prime}$ et suppose que le lapicide a corrigé 6568 (possible indiction 13 selon le comput byzantin) par 6551, année qui, «selon l'ère d'Alexandrie (1059, indiction 12) donnerait la date rectifiée». D'après J.-P. Rey-Coquais (1991-1992), le lapicide aurait gravé , $\varsigma \vee \eta^{\prime}$ (6558) avant de tracer un koppa au-dessus du $n u$ afin d'obtenir , $\varsigma \eta^{\prime}$ (6598), année qui correspondrait à l'indiction 12 à condition d'utiliser l'ère mondiale protobyzantine, dont le début précède d'un an celui de l'ère mondiale byzantine, pour calculer la date (1089). En 2009, le même auteur, tout en privilégiant cette interprétation, considère également que le graveur a bien pu inscrire,$\varsigma \varphi v \alpha^{\prime}$ (6551, soit 1043, en utilisant l'ère mondiale 
byzantine) tout en se trompant d'indiction (indiction 11 au lieu de 12). C'est cette dernière proposition qui paraît la plus vraisemblable: d'une part, comme le souligne J.-P. Rey-Coquais, l'erreur de datation indictionnelle serait compréhensible si l'épitaphe d'un moine décédé le 22 août, lors de la onzième indiction, a été gravée après le $1^{\mathrm{er}}$ septembre de l'année 1043, au début de l'indiction suivante; d'autre part, l'usage de l'ère mondiale byzantine est attesté à Gabala par l'épitaphe précédente et il est douteux que l'on ait utilisé deux computs différents dans la même ville à la même époque.

C. Mango, Deux inscriptions byzantines de Gabala en Syrie, TM 9, 1985, p. 464, no 2, ph. (D. Feissel, Bull. ép. 1987, 505; Idem, Chroniques, p. 194, nº 614); J.-P. Rey-Coquais, Inscriptions du Mont Admirable, Mélanges de l'Université Saint-Joseph 52, 1991-1992, p. 224-225, Appendice 2 (D. FeIssel, Bull.ép. 1996, 471 ; IDEM, Chroniques, p. 194, n ${ }^{\circ} 615$; J.-P. ReY-CoQuais, Pierre tombale médiévale, dans Choix d'inscriptions grecques et latines de la Syrie, éd. J.-B. Yon et P.-L. Gatier, Beyrouth 2009, p. 212-214, nº 64, ph.).

26. Fragment de quatre lignes brisé de toutes parts, non retrouvé dans la vieille ville de Jablé. L'éditeur copie TOBE[- - -]TOYK ... EBE $\Lambda$ TŎBA aux 1. 2-3 et considère que les 1.1 et 4 pourraient être rédigées en phénicien. En réalité, toute l'inscription est grecque. Sur la photo, on reconnaît sûrement le titre aulique byzantin de protovestès

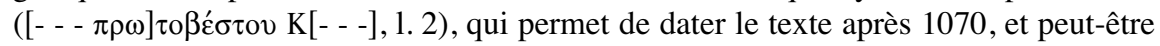
le nom de la cité thrace de Débeltos ([- - - $\Delta] \varepsilon \beta \varepsilon \lambda \tau$ ôิ BA[- - - ], 1.3 ; cf. P. SoustaL, Thrakien [TIB 6], Vienne 1991, p. 234-235 et 509, s.v. Debeltos). Le reste est obscur.

Th. RIIs, The Medieval Period, dans Topographical Studies in the Ğabla Plain, éd. P. J. RIIS et al., Copenhague 2004, p. 98, ph. P. Maurtvedt, fig. 138.

\section{LARISSA ( $\left.\check{S}_{\text {AYZAR }}\right)$}

27. Inscription gravée sur un bloc remployé dans la citadelle médiévale de Šayzar (et peut-être retaillé à cet effet) et composée, dans son état de conservation actuel, d'un nom (restitué $[\mathrm{M} \imath] \chi \alpha \eta^{\prime} \lambda$ dans $I G L S$ ) et d'une formule de datation correspondant au

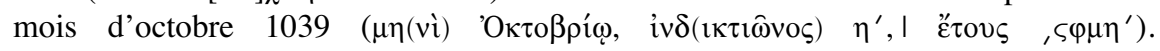
Récemment, N. Zorzi a proposé de considérer ce texte comme l'épitaphe d'un certain

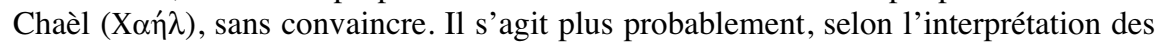
premiers éditeurs, d'une acclamation en l'honneur de l'empereur Michel IV le Paphlagonien (1034-1041), affichée par la garnison byzantine de Larissa ou par un de ses membres.

L. Jalabert et R. Mouterde, IGLS. IV, Laodicée, Apamène, Paris 1955, p. 98-99, nº 1377 (fac-similé), avec les corrections de V. Grumel, REB 14, 1956, p. 255, et de F. Dölger, BZ 51, 1958, p. 149 (J. et L. RoberT, Bull. ép. 1960, 397), reportées dans IGLS. V, p. 316; N. ZoRzI, Greek inscriptions from the citadel of Shayzar/Larissa and their historical context, dans Shayzar, I, éd. C. Tonghin, Leyde et Boston 2012, p. 55-59, ph., fig. 10.

\section{ÉDESSE D'OSRHOÈnE}

28. Inscription lacunaire de la porte de Harran, datée de l'époque où la cité est révoltée contre les Seldjoukides, sous Alexis I ${ }^{\mathrm{er}}$ Comnène, en 1094.

W. SAunders, The Greek Inscription on the Harran Gate at Edessa: Some Further Evidence, BF 21, 1995, p. 301-304 (D. Feissel, Bull. ép. 1997, 633; IdEM, Chroniques, p. 180-181, $\left.\mathrm{n}^{\circ} 568\right)$. 


\section{SERgioupolis (RUȘĀFA)}

29. Dédicace bilingue, grecque et syriaque, commémorant la réfection de l'église de la Sainte Croix (basilique A) sous l'autorité de Syméon, métropolite de Sergioupolis, au mois de juillet 1093 .

P.-L. Gatier, Les inscriptions grecques, dans Resafa. II, Die Basilika des Heiligen Kreuzes in Resafa-Sergiupolis, éd. Th. Ulbert, Mayence 1986, p. 169, nº 19. 